\title{
EL ARTESANADO EN LOS FUEROS DEL REINO DE MURCIA
}

\author{
José Damián González ARCE \\ Universidad de Murcia
}

\section{SUMARIO}

I. Fueros de la familia conquense: 1. El fuero de Cuenca. 2. El fuero de Alcaraz-Alarcón.- II. Fueros de la familia toledana: 1. El fuero de Toledo. 2. El fuero de Córdobe. 3. El fuero de Sevilla.- III. Otros fueros.- IV La ondenación foral del reino de Murcia: 1 . Villas de realengo. 2. Villas de señorio.- III. Conclusión.

En el reino de Murcia, donde se dio una gran permanencia de población mudéjar, fue la corona la que tuvo el protagonismo repoblador; instituyendo, para la administración de las zonas conquistadas, una serie de concejos de ella dependientes, que controlaron amplios alfoces. Estos concejos, daban cabida tanto a la población cristiana, inmigrada con fines repobladores, como a la población mudéjar; los fueros contemplaban los derechos de los pobladores cristianos, mientras que los de los mudéjares estaban recogidos en los tratados de capitulación. En los casos que la debilidad demográfica, o militar, impidió a la monarquía emplear este sistema repoblador, se hicieron concesiones territoriales a las ordenes militares, a la iglesia o a la nobleza, para la formación de señorios.

Los fueros no tuvieron como único fin el repoblador, también se encargaban de fijar los aspectos del derecho local, lo que coadyuvo a la propia repoblación, al poner de manifiesto de forma explícita y por escrito el estatuto legal de los vecinos, esto es, las franquicias a disfrutar por 
quiénes fuesen de tal calidad, atrayendo asl a nuevos repobladores. Podemos considerar al fuero como un conjunto de garantfas que el señor del lugar al que se otorga ofrece a sus pobladores. Estas garantias irlan en detrimento de los propios derechos señoriales, amparados por argumentos legales, de tradición, herencia, propiedad o conquista. En el caso de la monarquia repobladora se mezcla un doble ámbito, el señorial o privado, y el estatal o público. El rey es "señor" de cuanto ocupan sus ejércitos, lo que le pertenece por derecho de conquista; y, si hace cesiones o concesiones es solo para atraer repobladores. Estas remisiones de sus derechos se compilaron en forma de fueros. Pero, el rey es a la vez el administrador de los territorios ahora anexionados a la corona, al estado, y debe poner por escrito, en un fuero, las obligaciones de los súbditos que alli se avecinen; según el romanismo emergente del siglo XIII' ${ }^{1}$. Existen también fueros de origen señorial, eclesiástico o nobiliario; asI como concejos de esta naturaleza.

No podemos olvidar la tarea emprendida por la corona castellana, incrementada en el siglo XIII, para intentar conseguir una práctica centralización del poder polftico. Se procedió ası a la aniquilación de las instituciones que, en relación con los estilos convencionales del feudalismo clásico, suponfan formas de autogobierno de su respectiva clase señorial, o incluso de autoadministración de comunidades, tanto urbanas como campesinas. La base de esta actuación fue el "Ius Commune" romano-canónico, bastante maleable y aplicable a la estructuración de una sociedad compleja de base señorial, donde aún cabla la nobleza y caben plenamente las ciudades, como comunidades con un nudo corporativo de artesanos y mercaderes. Esta politica real encontró una resistencia en el derecho foral. Los fueros representan un ordenamiento social de base señorial e impronta comunitaria, con escasos niveles de admisión de los órdenes eclesiástico y monárquicoº ${ }^{2}$ pero

\footnotetext{
'Salvador de MOXO, Repoblación y sociedad en la Espara cristiana medieval, Madrid, 1979, pp. 383-384; aparte de sus implicaciones germánicas, los fueros castellanos arrancan del Derecho visigodo, a través del Fuero Juzgo, las costumbres, los privilegios reales y nomas concejiles; pero no serian ajenos tampoco a la legalidad privada, comprendida en el derecho curtense. Sin embargo, parece desecharse para el caso castellano la implicación agricola-territorial del término "fuero", relacionándose con actividades del derecho y la justicia (Juan Antonio SARDINA PARAMO, El concepto de Fuero. Un análisis filosófico de la experiencia juridica, Santiago de Compostela, 1979, p. 35).

${ }^{2}$ Bartolomé CLAVERO, Signo social y secuela politica de la legislación alfonsina. Planteamientos manualísticos, "España y Europa. Un pasado jurídico común", Murcia, 1986, pp. 605 606.
} 
que acabaron sucumbiendo ante la preponderancia de la posterior legislacıón real.

Por lo que respecta a la relación entre artesanado y fueros, si en el norte de la península Ibérica los artesanos pudieron ocupar puestos de consideración en la ciudad, no ocurrió así en la Meseta, donde las estructuras economicas y sociales no les eran favorables y estaban apartados de los cargos municipales. El artesanado estaba sometido al control de las autoridades concejiles, tal y como lo recogen los fueros; siendo precisamente dichas autoridades las que menospreciaban a este sector de la población, porque en las citadas zonas los intereses economicos preponderantes, que se encargaban de proteger los fueros, eran la agricultura y la ganadería, estando el grupo dominante formado por terratenientes, que apenas se ocupaban de lo que no estaba directamente relacionado con la tierra; pero que al mismo tiempo no renunciaron a procurarse aquellos productos manufacturados que precisaban, al mejor precio, por lo que también apareció regulada la actividad artesanal, imprescindible en toda comunidad urbana.

De este modo, los ordenamientos forales recogen aspectos de la intervencion del concejo en la actividad economica, tales como: la ubicación jurídica de los menestrales, dentro del conjunto de vecinos, y en la defensa frente al exterior, de acuerdo con el localismo de la época y del derecho; en cuanto a la producción en sí, en lo referente a sus métodos, calidad y características; respecto a la comercialización de los productos, precios, pesos y medidas, o vigilancia del mercado; y, en cuanto a la existencia de agrupaciones gremiales o de cofradías.

Dentro de la logica del sistema feudal, la clase dirigente se sirvió de los concejos, y de los textos forales, para marcar la pauta de la explotación economica del artesanado, con arreglo a sus propios intereses de obtención de una producción barata y de calidad, mediante el control de la actividad económica o a través de la exigencia de exacciones fiscales. En el ámbito foral, la reglamentación de las actividades artesanales tenía como objeto dar garantías a los consumidores, a base de principios generales o incluso minuciosas normas técnicas. También se establecían las condiciones del trabajo, mediante contrato o venta pública; su forma de pago; o los plazos 
de producción ${ }^{3}$. Otros fueros contienen disposiciones relativas a la propiedad de los medios de producción, exenciones y exacciones fiscales o ubicación espacial del artesanado.

Ocupándonos ahora del concejo, recordemos aquella visión ya clásica que de él se tenfa con señorfo colectivo, en el que sus dirigentes serfan el señor o noble y el alfoz, con su población, el señorío de su jurisdicciont. Todos los vecinos gozaban, dentro del mismo, de una igualdad de derechos según cada estamento social. La ciudad controlaba al alfoz, en el que se engloban numerosas villas, cuya población tenfa sin embargo inferiores derechos. La primera localidad en ser dotada de término concejil, dentro del reino de Murcia, fue Alicante, en 1252; a la cual siguieron Mula y Cartagena; más tarde lo serfan las restantes, dentro de los Ifmites territoriales del obispado de Cartagena, recogidos en un documento alfonsinos.

Tres elementos definen y diferencian a los concejos murcianos del siglo XIII: fueros y privilegios; términos o jurisdicción territorial; y, quiénes constituyen y gobiernan el concejo. Por lo que respecta al gobierno urbano, no todos los vecinos tenfan la misma capacidad para acceder a él. Se asignaba ésta en función de la categoría social, ocurriendo que en algunos casos, como en la vecina villa de Alcaraz, los artesanos estaban explicitamente relegados de esa posibilidad. Son los fueros y privilegios los que marcan estas diferencias, coincidiendo en la asignación paritaria de los jurados a los tres grupos sociales típicos de la primera repoblación: caballeros, escuderos y peones. Según las disposiciones reales, todos los vecinos integraban la asamblea concejil, aunque no todos podian ser elegidos para los puestos rectores; lo que implica que a las asambleas del concejo abierto sólo

\footnotetext{
3Jean GAUTIER DALCHE, Historia urbana de León y Castilla en la Edad Media. (Siglos IXXIII), Madrid, 1979, p. 437-438. Maria del Camen CARLE, Del concejo medieval castellanoleonés, Buenos Aires, 1968, pp. 216-217. Para un trabajo sobre el contenido artesanal en los fueros concedidos a las villas al sur del Tajo, vid. Tomás PUÑAL FERNANDEZ, La organización del trabajo en la normativa juridica del siglo XIII; el ámbito castellano-manchego, "IX Jornades d'Estudis Historics Local. La manufactura urbana i els menestrals (ss. XIII-XVI)", Palma de Mallorea, 1991.

"Gina FAsOU, Ciudad y feudalidad, "Estructuras feudales y feudalismo en el mundo moditerranco", Barcelona, 1984.

SJuan TORREs Fontes y Angel Luis MOUNA MOLNA, Murcia castellana, "Historia de la región murciana", III, Murcia, 1980, pp. 339-340. Vid. María MARTINEZ MARTINEZ y Angel Luis Mouna Mouna, Delimización de los términos concejiles del reino de Murcia, "MisceKnea Medieval Murciana" (en adelante "MMM"), XIII, 1986. "Colección de Documentos para Ia historia del Reino de Murcia" (en adelante "CODOM"), Academia Alfonso X el Sabio, I, p. 37 (Sevilla, 11-XII-1266).
} 
acudiŕa una parte de los vecinos ${ }^{6}$. En cualquier caso, las autoridades urbanas ejercían su poder por delegación real, dependiendo del monarca $o$ de sus representantes.

Los magistrados concejiles más directamente relacionados con la actividad artesanal eran los jurados. Su misión consistía en estar presentes en todos los actos del concejo, protegiendo a los vecinos de la ciudad y teniendo a su cargo collaciones y parroquias. Ejecutaban acuerdos concejiles y resolvian problemas cotidianos. Controlaban al almotacén y realizaban cersos de vecinos de carácter fiscal, para evitar los excesos de los recaudadores, controlando asimismo el gasto del concejo. Aparte de oponerse a los excesos de la oligarquia gobernante, por lo que eran elegidos entre todas las categorías sociales, los jurados se centraban en actuaciones económicas, procurando el cumplimiento de las ordenanzas y vigilando el mercado, tiendas y otras tareas urbanas, como la limpieza?. Por lo que respecta al almotacén, las funciones a él atribuidas variaron también, como para los jurados, según los concejos, no coincidiendo en aquellos con distintos ordenamientos forales. De forma genérica, se ocupaba del ámbito económico del mercado, controlando pesos y medidas y castigando fraudes. También se encargaba del orden, seguridad y limpieza de la ciudad.

\footnotetext{
${ }^{6}$ Si la concesión de amplios alfoces a los concejos castellanos en el siglo XII tuvo una motivación económica: proporcionar a los pobladores suficientes recursos, pastos sobre todo; en el siglo XIII, también es importante la capacidad colonizadora de los concejos, manteniéndose aproximadamente los términos de época musulmana (J. TORRES FONTES, Evolución del concejo de Murcia en la Edad Media, "Murgetana", 73 (1987), pp. 9, 13, 17). Finalmente el concejo abierto fue sustituido por el cerrado o el reducido, donde esta oligarquía asumió de forma permanente o rotativa los puestos rectores; en el caso de la ciudad de Murcia, a partir de 1325. Por lo que respecta a estos concejos abiertos, típicos de este periodo, decir que se los ha venido considerando, erróneamente, como paraisos democráticos enquistados en un ordo feudal; pretendidamente en ellos todos los vecinos habrian gozado de igualdad de voz y voto, así como de similares posibilidades políticas; estos utópicos concejos serian el complemento ideal de una naciente monarquía centralizada, apoyada en la incipiente "burguesía" urbana, frente al estatismo nobiliario. Pero en realidad, la asamblea de vecinos se vio mediatizada por una oligarquía que controlaba el poder urbano, político y económico, a través de las magistraturas y puestos rectores (J. GAUTIER DALCHE, cit., p. 34 y ss.).

'J. TORRES FONTES, El estatuso concejil murciano en el siglo XII, "CODOM", II, 1969, p. XL de la introducción. La elección de los magistrados correspondía al concejo amplio, sólo tenian derecho a voto o a ser elegidos los hombres buenos; esto es, hidalgos, caballeros y aquellos "abonedos" cuyos bienes les permitieran distinguirse de los menestrales, los peones o los pecheros [Sobre los "hombres buenos" vid. María del Carmen CARLE, "Boni homines" y hombres buenos, "Cuadernos de historia de España", XXXIX-XL (1964). J. TORRES FONTES, Evolución cit., p. 19.
} 


\section{Fueros de la familia conQuense}

Se trata de una serie de fueros del tipo extenso. En ellos se hallan regulados casi todos los aspectos de interés para el desarrollo de la vida concejil, de forma amplia y a veces exhaustiva. Entre otros, las actividades económicas y dentro de éstas las artesanales. Contienen amplias ventajas jurf́dicas para sus pobladores, con las que asegurar una difícil repoblacion frente al peligro musulmán. Con este fin fueron concedidos en Murcia y Andalucía, aunque pasada la situación fronteriza sufrieron cierta desvirtuación. En materia económica, la inseguridad fronteriza predispuso a la preponderancia de la ganadería sobre la agricultura, al radicar ésta sobre bienes semovientes, fácilmente defendibles tras las murallas urbanas o transportables en la huida. De esta actividad ganadera se derivo cierta actividad textil lanera, inspirada en el fuero y en sus derivados por una normativa laboral igualmente extensas.

En el reino de Murcia, dos son las variantes de esta familia que nos interesa estudiar. El propio fuero de Cuenca, concedido a algunas villas, o su variante de Alcaraz-Alarcon, otorgada a otras.

\section{El fuero de Cuenca}

En el seno de este ordenamiento jurídico la actividad productiva y comercial de carácter urbano parece haber alcanzado el más amplio grado de libertad y potencial desarrollo, al mismo tiempo que las exacciones fiscales se presentan claramente disminuidas. Este marco juridico general se ajusto, tras la conquista de los territorios manchegos, a las necesidades del poder político, y fue la base según la cual potenciar, con mercedes ampliadas, la atracción de repobladores, y entre ellos a artesanos y comerciantes. Téngase en cuenta que, además, en la zona de aplicación de este fuero, el

\footnotetext{
'Paulino IRadiel MURUgarren, Evolución de la industria textil castellana en los siglos XIII-XYI. Factores de desarrollo, organización y costes de la producción manufacturera en Cuenca, Salamancs, 1974, p. 42. Entre las principales caracteristicas de los fueros conquenses podemos citar: un ofrecimiento de libertad en los concejos, que estarían fuera de la dependencia de la noblezs y ordenes militares o monáticas; posibilidades de organización del propio gobiemo, a travé del nombramiento de alcaldes, juez y cacribano; quedando fuera del poder el delegedo regio. Esta organización administrativa $s e$ completa con una serie de amplias ventajes y exenciones fiscales (Mariano PESET REG, Los fueros de la frontera de Albacele: una inserpretación histórica, "Congreso de Historia de Albacete", II La Edad Media, Albacete, 1984, p. 31).
} 
elemento mudejar que permanecio tras la conquista, salvo excepciones, no tuvo una importancia de consideración.

El fuero de Cuenca y sus derivados constituyen la más amplia concesión de exenciones y de posibilidades de organización propia. Aparte de una exención genérica de todo tributo, evidentemente no llevada a la práctica, el fuero eximía del pago de montazgo y portazgo a los vecinos, e implícitamente de almojarifazgo. A la vez que en el plano teórico la libertad e igualdad de los pobladores se daba por encima de diferencias grupales 0 de clase; el nuevo poblador quedaba libre de sus anteriores lazos dependiendo únicamente del rey a través de un alcalde o de un merino'.

El comercio y la producción artesanal estaban, además, alentados de forma explícita: se libero de prendas, salvo por deuda o fianza, a todo el que acudiese con mercancías a la población; se concedió una feria de 17 días en la que se ofrecía seguridad personal, pero no exenciones especiales; se instituyo la figura del corredor; asf como la libertad de compra-venta, o alquiler, de inmuebles y mano de obra.

Por lo que respecta a esta última, se admite la esclavitud de mudéjares, al equipararse el empeño de un bien ráz al de un "moro menestral", capaces ambos de generar una renta y un usufructo, así como de ser empeñados y desempeñados. En cuanto a los medios de producción inmuebles, aparecen detalladamente bien estructurados. Su propiedad es de libre disposición para los vecinos: "cualquiera que posea un bien ralz, téngalo firme y estable y sea suyo para siempre", con la única limitación de que no fuesen enajenados a la Iglesia; pudiéndose además efectuar en ellos toda clase de reformas, sin limitación alguna. Son de propiedad particular hornos, molinos, canales y presas. Comunal, canteras y yesares. $Y$ mixta, los poyos de las calles a las puertas de las tiendas. La detallada y minuciosa reglamentacion referente a los molinos aseguro su libre disposición para sus propietarios, base fundamental para su desarrollo y proliferación, lo que permitio

\footnotetext{
'El Fuero de Cuenca, ed. de Antoniuo Valmara Vicente, Cuenca, 1978, pp. 32, 33, 38, 41, 43. José Damián GONZALEZ ARCE, Fiscalidad y economia urbana en los fueros de Cuenca y Alcaraz, "El Fuero de cuenca y su tiempo. Coloquio", (en prensa); precisamente la no exigencia del almojarifazgo es lo que marca la personalidad fiscal de la familia de fueros toledanos.
} 
la rápida progresión de la producción textil, que no podría entenderse sin la utilización del batán ${ }^{10}$.

Aparte de las libertades, exenciones y acceso a la propiedad, genéricos, el fuero reglamenta de forma explícita cada actividad artesanal. Con ello el artesano cobra entidad, reconociéndosele un valor y utilidad para la comunidad ciudadana. Queda asi superada en parte la anterior consideración de gentes viles que viven por sus manos, para adquirir el rango propio de una parte integrante del engranaje social, que el fuero eleva a una utilidad funcional de carácter contractual. Cada actividad artesanal responde a un principio contractual, según el cual cualquier vecino encargaba la realización de la misma al artesano de su elección, quién respondía de ésta según las condiciones que dispone el fuero y los compromisos acordados. Este principio es totalmente ajeno a la libre iniciativa de producción para el mercado, mientras que es la base de la forma doméstica de producción textil que caracteriza este periodo, y de toda la producción artesanal en general; la cual, en la mayoría de los casos se realizaba por encargo, teniendo el menestral la responsabilidad de su obra sin tener libertad para la fijación de los precios de venta ${ }^{11}$.

Desde la construcción de una casa, a la confección de unos zapatos o ropas, se realizaban por encargo; según condiciones de trabajo, obraje, calidad, duración... preestablecidas y amparadas en el marco jurídico foral. La contravención de las mismas por alguna de las partes implicaba la imposición de una serie de penas pecuniarias. Resulta un rasgo de primitivismo el que el fuero contemple casi en exclusiva el trabajo por encargo, lo que a la vez fomenta el corporativismo al aparecer el productor alejado de la propia iniciativa y del mercado. Ello es a la vez una ventaja para la autoridad política, porque le permite, a través del almotacén, controlar la actividad productiva, vigilando el cumplimiento de las disposiciones normativas y contractuales. En esta actividad de sujeción y control no sólo estuvieron implicados los funcionarios concejiles, sino también la generalidad de los

\footnotetext{
${ }^{10}$ El Fuero... cit., pp. 239 y 47 . Se han puesto en relación tres variables, las ventajas forales, la disponibilidad de factores naturales y materias primas, y la introducción del cambio tecnológico, para comprender la aparición y desarrollo de la producción textil en Cuenca (P. IRADIEL, cit., pp. 45-48). Vid., Santiago AGUADE NIETO, Molino hidráulico y sociedad en Cuenca durarie la Edad Media (1127-1300), "Cuenca y su territorio en la Edad Media". Actas del I Simposio intemacional de Historia de Cuenca, Madrid-Barcelona, 1982.

"P. IRADIEL, cit., p. 44. M.C. CARLE, Mercaderes en Castilla, "Cuademos de Historia de Esparis, XXI-XXII", p. 183.
} 
consumidores, que, a través de la denuncia del incumplimiento de los acuerdos por parte de los artesanos, se convirtieron en agentes del sistema de control de los productores.

Según el fuero, el almotacén era el encargado de controlar la actividad en el mercado: el correcto uso de pesos y medidas, la calidad de la producción, precios, limpieza... Este puesto, aunque en ocasiones lo ocupen ex oficiales concejiles, tiene la consideración de funcionario asoldado y responsable de sus actuaciones ante la autoridad; no fue infrecuente su arrendamiento, pues aparte del salario, el funcionario solía participar de las penas pecuniarias que el mismo imponía a los contraventores de la normativa, según su determinación; causa del celo puesto en la persecución de fraudes. Por su parte, al artesano le quedaba el recurso de apelar las actuaciones del almotacén ante la autoridad concejil, no siendo infrecuentes los abusos.

Por lo que respecta a los pesos y medidas, si bien el almotacén debra inspeccionar aquellos pertenecientes a tenderos, panaderos, olleros, tejeros, ladrilleros, mercaderes...; a los vecinos se les concedio la facultad de tenerlos libremente en sus casas, no existiendo ningún monopolio o limitación sobre su uso. La única condición era la de superar las correspondientes inspecciones semanales; que bien podrían ser utilizadas para encubrir una estrecha fiscalización sobre la producción y los productores.

Las distintas categorías de menestrales: "maestro", "criado", "asalariado", no atienden a una jerarquización de corte gremial. El maestro era el dueño del taller, que, trabajando generalmente en solitario, a veces podía emplear a algún criado o asalariado. Sin embargo, el fuero contempla, para el oficio de los zapateros, la existencia de un "preposito" o "preboste", figura de implicaciones gremiales: pues, como el almotacén participaba de las penas pecuniarias, cobrando un maraved de aquel zapatero que emplease materia prima fraudulenta, tomándole además prendas a aquel otro que no acabase bien las suelas; si este preboste no quería hacer justicia, el almotacén debra tomarle prendas por valor de $2 \mathrm{mrs} .{ }^{12}$.

Finalmente, refiramos dos aspectos económicos también recogidos en el fuero. Uno, la existencia de precios prefijados por la autoridad local. El otro, las multas por contravención de la normativa, como única fuente de

\footnotetext{
${ }^{12}$ El Fuero, cit., p. 276.
} 
apropiación de excedentes de tipo especifico, esto es, la única renta feudal que gravaba la actividad productiva artesanal, según la letra del fuero.

\section{El fuero de Alcaraz-Alarcón}

Aparte del texto del fuero amplio de Alcaraz-Alarcón, variante y derivación del de Cuenca, habremos de referirnos aqui a algunos otros aspectos jurídicos contenidos en el privilegio de concesión del fuero de Cuenca a Alcaraz, y que con ello quedaron así incorporados al derecho local de esta última.

Este fuero no es una transliteración del conquense, que no se aplico en toda su extensión ni aún en la propia Cuenca, sobre todo en lo relativo a las excepcionales exenciones fiscales. Se habrá de considerar pues que, sólo aquellos privilegios y ventajas concedidos de forma explícita fueron los únicos en aplicarse en Alcaraz, pese a que se mantenga la vigencia del esprritu foral como marco teórico general. Algo similar fue lo ocurrido al aplicar el fuero de Cuenca a las villas murcianas, en su versión original o en su variante de fuero de Alcaraz, sobre todo en el caso de las villas de señorfo. No faltan tampoco las quejas relativas a cómo el fuero se aplicó mal en numerosas ocasiones y circunstancias.

En el caso de Alcaraz, la exención de portazgo, ya contenida en el derecho conquense, si se respetó y se hizo más generosa, quedando ampliada a toda Castilla y no sólo al sur del Tajo; el número de ferias fue aumentado a dos por alfonso $X$ en 1268. Pero, la más grave agresión que sufriera el derecho local de la villa, en detrimento del ordenamiento conquense, fue su intento de sustitución por el más restrictivo Fuero Real; intento tras el cual, una vez fracasado, el antiguo fuero de Alcaraz sólo fue repuesto parcialmente $^{13}$. Contraria al fuero, por ejemplo, igualmente fue la existencia de un peso mayor perteneciente al rey, asi como la de un peso del mercado, que también se reservó para sus rentas el monarca. Tampoco faltan contravenciones de carácter social, no se mantuvo por ejemplo el igualitarismo de los vecinos, al copar la nobleza los puestos de gobierno e introducirse como gran propietaria; algo similar a lo efectuado por la iglesia, que sin ser sede

\footnotetext{
${ }^{13}$ Aurelio PRETEL MARIN, Conquista y primeros intentos de repoblación del territorio albacetense. (Del periodo islámico a la crisis del siglo XIII), Albacete, 1986, p. 94; y, Alcaraz. Un enclave castellano en la frontera del siglo XIII, Albacete, 1974, pp. 143-146.
} 
episcopal emprendio la construcción de palacios ${ }^{14}$. Manifiestamente contraria al fuero fue además una de las normas dictadas por Fernando III, al prohibir a los menestrales participar en las suertes para la elección de juez, debido a su vil y rahez condición que podía acarrear la vergüenza colectiva ${ }^{15}$. También, en contra del fuero, los vecinos pagaban gran cantidad de tributos reales, porcentajes de los cuales fueron destinados a la iglesia y a la oligarquía local.

En 1213 Alfonso VIII conquistó Alcaraz, dotando a la villa con el ventajoso fuero de Cuenca. El derecho conquense adoptó matices peculiares en Alcaraz, al igual que en Alarcon donde igualmente se aplico, dando lugar a la aparición de un nuevo marco jurídico con personalidad y características propias. Como en el caso de Cuenca, ambos fueros contemplan la exención de pechos para los vecinos de la villa, excepto en el caso de las murallas. Esta se torna más explícita cuando queda franqueado el pago de portazgo y montazgo; del primero en toda Castilla para Alcaraz, y al sur del Tajo para Alarcón. Sin embargo, en las villas sí se cobraba portazgo de las mercancias traidas por los mercaderes que no fuesen vecinos o que compraren alli las mismas. Esta renta quedo dividida en dos variantes: el hostelaje y el portazgo propiamente dicho. Ambas gravaban gran cantidad de artículos artesanales y materias primas utilizadas en su confección: paños, cueros, lino, fustanes, ollas, zumaque, lana... ${ }^{16}$; son de destacar la gran variedad de paños contenida en las relaciones, as 1 como las materias primas empleadas en esta industria.

Por lo que respecta a los medios de producción inmuebles, éstos estaban, como en Cuenca, en poder de los particulares, quiénes los podían vender, comprar o cambiar libremente, excepto a la iglesia. La única condicion impuesta era la de pregonar la venta y dar un derecho preferente de compra de tres dfas a sus familiares. Los contratos de alquiler, de casas o tiendas, podían ser anuales o mensuales, y si el que la alquilaba la quería

\footnotetext{
${ }^{14} M$. PESET, cit., Pp. 33 y 41.

${ }^{15}$ A. Pretel, cit., p. 138 (Sevilla, 25-XI-1245).

${ }^{16}$ Para el estudio de los fueros utilizaremos la edición de Jean Roudil, Les Fueros D'Alcaraz et D'Alarcón, París, 1962. El caso de la villa de Alarcón es distinto al de Alcaraz, pues, aunque ambas villas permanecieron fuera del reino de Murcia, el fuero de la primera apenas si fue concedido a alguna villa murciana de poca entidad, mientras que el de Alcaraz encontrara una amplia difusión en este ámbito regional. Por este motivo hemos prescindido aquí del estudio del fuero de Alarcón como tal, debido también a la gran similitud que guardó con el de Alcaraz. Sobre el portazgo, ibidem, pp. 86-87, 571-583.
} 
abandonar, debra buscar a otro que ocupase su lugar y cumpliese las condiciones del contrato. Las calles eran del concejo, como en Cuenca, y si en ellas se construla algún poyo, éste pertenecla por igual a dicho concejo y al dueño de la casa o tienda, no pudiendo en ningún caso alquilarlo. Se fijan además las condiciones de existencia de hornos, cocción del pan y sus derechos; y la construcción de molinos, presas y acequias; observándose una gran libertad solo limitada por los perjuicios que se pudieran derivar para otros vecinos o la colectividad"

El almotacén se debra ocupar de las medidas del pan, vino, aceite y sal; ası como de las pesas y libras. También debra ocuparse de los carniceros, tenderos, olleros, tejeros, ladrilleros y revendedores. Tenía además que prestar juramento ante el concejo sobre la fieldad de su cometido o los precios fijados por éste último. Las penas impuestas por el almotacén tenfan el siguiente destino: un tercio a repartir entre el propio almotacén y el denunciante y dos tercios para el concejo, para las murallas. La pena impuesta al funcionario por incumplimiento de su cometido se elevaba a 10 mrs. Cualquier vecino podra tener en su casa pesos y medidas, sin pagar derecho alguno, siempre que fuesen correctos ${ }^{18}$.

La persona que quisiese vender alguna cosa debra tomar al comprador como su fiador y deudor, y si éste no cumplia los plazos y condiciones de la venta podía denunciarlo; los compradores también podfan utilizar un fiador. Los tenderos y revendedores debfan vender y comprar sus mercancias a los precios fijados por el concejo; $y$, cualquiera que fuese tendero, revendedor, carnicero, pescador, vinatero, zapatero, sastre, pellejero, tejedor o cualquier otro menestral que el coto no quisiera guardar, debla pagar una multa de 2 mrs., si le era probado, aunque se libraba si dos vecinos atestiguaban en su favor. En el caso de demandas sobre productos artesanales robados, tales como paños y vestidos, se hacia intervenir a los menestrales que los confeccionaron ${ }^{19}$.

Por lo que respecta a dicha confección, ocurre algo similar a lo que vimos para Cuenca. Predomina el trabajo por encargo, según acuerdo contractual que se ha de respetar hasta la conclusión de la obra, según las

\footnotetext{
${ }^{17}$ Ibidem, pp. 458 459, 462, 58, 115, 163-171 у 172.

"Ibidem, pp. 304-305 y 307.

${ }^{19}$ lbidem, pp. 457, 543, 517.519.
} 
condiciones prescritas ${ }^{20}$. Se fijan condiciones de trabajo para carpinteros y tejedores, que debran enmendar sus propios errores; herreros, a la hora de herrar a los animales o por fraudes en las herramientas; orebzes o argenteros, sobre la calidad de la obra acabada o el peso del material entregado. Los fraudes cometidos por los zapateros debran ser aterididos por su preboste, que, como en Cuenca, puede ser una figura de condición gremial, especie de alcalde o alamín elegido en el seno del oficio. Se continúa con más normas técnicas para prevenir posibles fraudes de pellejeros, sastres, tejedores, vendedores de telas, olleros, tejeros y ladrilleros. Tambien se fijan los precios de algunos productos, como ladrillos y ollas ${ }^{21}$.

Los fueros se ocupan asimismo de las condiciones de contratación de los obreros alquilados o de los sirvientes asalariados. Como en Cuenca, los moros menestrales tenían la condición de bienes raíces, porque como éstos eran suceptibles de producir una renta, a la vez que se podían empeñar. Para proteger el trabajo de los menestrales locales, asegurando su monopolio productivo, el fuero castigaba a los menestrales foráneos que fuesen sorprendidos trabajando en los términos de la villa; la pena era la de cárcel hasta su remision; "esto fazemos por que los menestrales vezinos mas ganen", y los aldeanos acudiesen al mercado de la villa ${ }^{22}$.

\section{Fueros de la familia toledana}

A diferencia de la conquense, la toledana es una familia de fueros breves con una menor amplitud de privilegios y ventajas para los pobladores. En los ordenamientos toledanos son más marcadas las diferencias jurídicas entre las clases sociales, también es mayor la autoridad real y su capacidad para extraer rentas fiscales de la población asentada.

\footnotetext{
${ }^{20}$ Se cita el caso de los maestros que comenzaren torres, iglesia, libro, puente, casa, molino u otra labor. También se aclara como se debía actuar hasta finalizar la obra, si muriese el maestro, o la pena por no finalizarla a tiempo (Ibidem, 530 y 88.).

${ }^{21}$ Bbidem, 534-541.

${ }^{2}$ Ibidem, 584, 488-489, 460, 520. La disposición foral que precede a esta de los menestrales foráneos es una curiosa normativa sobre las cofradías; no sabemos si se puede otorgar a las mismas un carácter gremial, pero, quién fuese prendado por hecho de una de ellas, si se querellabe al juez o alcaldes ordinarios se le devolvía la prenda doblada, pero debía pagar al juez 10 mrs. (ibidem, 249).
} 
Se trata, como decimos, de fueros breves, con una extensión tal que los hace coincidir con las cartas de privilegio mediante las cuales fueron otorgados. El fuero de Toledo, concedido para la repoblación de la ciudad de la que tomó el nombre. se otorgó a Córdoha y luego a Sevilla; bajo la denominación de "fuero de Córdoba" o "fuero de Sevilla", se concedió a las villas murcianas, como instrumento con el que homogeneizar su repoblación. Se trató de una política de unificación jurídica, emprendida por Fernando III y continuada por Alfonso $X$ y sus sucesores; con la que se trato de respetar el primitivo derecho local a la vez que conceder un derecho único y uniforme a los nuevos pobladores, utilizando como base primero el Fuero Juzgo y luego mediante el intento de introducción del Fuero Real y Las Partidas. Esta polftica uniformadora se aprecia claramente en el reino de Murcia, en la concesión de los derivados del Fuero Juzgo a las villas del sur, mientras que en las del norte se intentó sustituir los textos forales de la familia conquense por el Fuero Real. Los fueros, al ser concedidos a las villas, solían estar contenidos en privilegios rodados, en los que se inclura tanto la reproducción. Integra o parcial, del fuero de Toledo, así como ciertas variantes; entre éstas se encuentran las alusiones al texto del Fuero Juzgo, base jurídica del derecho toledano, utilizado como un código suplementario, sobre todo en materia penal y procesal $^{23}$.

\section{El fuero de Toledo}

Este fuero, como tal, no fue directamente concedido a ninguna villa murciana, con la excepción de que se aplicó a la élite dirigente asentada en Cartagena ${ }^{24}$, al igual que en Orihuela, mientras que al resto de la población se aplico el fuero de Córdoba. Pero su contenido se reprodujo con variantes en los textos sevillanos y cordobés, por lo que las referencias que contenga

\footnotetext{
${ }^{23}$ Antonio Garcia-Gallo, La obra legislativa de Alfonso $X$, "Anuario de Historia del Derecho Español" (en adelante "AHDE"), 46, 1976, p. 261. Joaquín CERDÁ, Principios del derecho comin en los derechos locales del antiguo reino de Murcia, 1245-1284, "España y Europa" op. cit., pp. 708-709.

${ }^{24} \mathrm{~J}$. TORRES FONTES y A. L. MOUNA MOUNA, cit., p. 307; son los mejor heredados, a los que corresponde una función esencial, que es la propia de esta clase social, la de las annas (J. TORRES FONTES, El concejo de Carzagena en el siglo XIII, "CODOM", V, 1978, p. XV de la introducción). El privilegio de concesión aclara que va referido a los burgueses, marineros y balleateros que mantuviesen caballo, armas y navíos armados; a los que se conceden los fueros y franquezas de los que gozaban los hidalgos de Toledo ("CODOM", III; p. 54, Monteagudo, 6-V-1257).
} 
relativas al mundo artesanal serán estudiadas directamente en estos últimos, que son los que se aplicaron en el reino de Murcia.

Sin embargo, convendrá aquí efectuar una serie de reflexiones que pueden aclarar el origen de ciertas exacciones fiscales, franquezas o instituciones relacionadas con el artesanado, y que, a través del derecho toledano, pasaron a Murcia ${ }^{25}$. Es triple la influencia que determina el derecho toledano y sus implicaciones económicas: la musulmana, la mozárabe y la castellana. De ella se derivan fenómenos tales como el diezmo fiscal, de origen islámico; el almojarifazgo, con un mismo origen; o los mesones, almacenes, tiendas y pesos de propiedad real. Igual de interesante es la afirmación que habla de que Toledo conservó una organización económica urbana recibida de la época anterior a la conquista, la cual transmitió a otras ciudades castellanas a lo largo de los siglos XII y XIII. Y es que esta organización heredada hizo que los conquistadores y pobladores de las ciudades andaluzas y murcianas ya estuvieran familiarizados con sus sistemas de organización aún antes de la conquista, así como predispuestos a su mantenimiento. De forma que, en el ámbito artesanal, los distintos oficios estuvieron organizados a través de alamines, también llamados alcaldes o veedores; se trató de autoridades internas que controlaban calidades y precios, asi como dirimían conflictos en el seno del oficio. Se ha de tomar esta evidencia como muestra de la raf́z islámica del gremialismo castellano. Esta influencia no se limita sólo a la reproducción de gremios con autoridades propias, sino que se extiende también a la concentración de la actividad económica en zocos, según especialidades laborales ${ }^{26}$.

\footnotetext{
${ }^{25}$ Para una edición del fuero vid. Alfonso Garcta-GaLLO, Los Fueros de Toledo, "AHDE", 45 (1975). La configuración del fuero de Toledo atiende a una serie de concesiones jurídicas realizadas por la monarquía, a partir de la conquista de la ciudad por Alfonso VI. Aparte de la gran presencia de castellanos y francos desde la misma, es de destacar además la de los mozárabes; que se regían por un fuero especial otorgado por el propio Alfonso VI, así como, en asuntos intemos, por el antiguo derecho hispanogodo ("Liber ludiconum"). Del Derecho de los castellanos queda constancia a través del fuero de Escalona; y del de los francos mediante una confirmación de 1136, que se refiere a su barrio y actividades económicas. Imponiéndose sobre todos, finalmente, el Fuero Juzgo mozárabe [Miguel Angel LADERO QUESADA, Toledo en la época de la frontera, "Anales de la Universidad de Alicante. Historia Medieval" (en adelante "AUAHM"), 3 (1984), pp. 82-83; vid. Ricardo IZQUIERDO BENITO, Los privilegios reales de Toledo en la Edad Media, "En la España Medieval", 13 (1990)].

${ }^{26}$ M.A. LADERO QUESADA, cit., p. 85; J. GAUTIER DALChE, cit., p. 423. Dicha influencia se debió a la reproducción jurídica del derecho toledano, más que a una imitación de lo encontrado en las villas sometidas, lo que explica la similitud de situaciones en las distintas villas aforadas al modelo toledano [J.D. GONZÁLEZ ARCE, Sobre el origen de los gremios sevillanos, "En la España Medieval", 14 (1991)].
} 


\section{El fuero de Cordoba}

En 1241, Fernando III concedio a Córdoba el fuero de Toledo ${ }^{27}$, pasando asi a denominarse "fuero de Cordoba". En él se aprecian las siguientes referencias relativas a la actividad artesanal:

El fuero concede tanto al concejo como a los magistrados urbanos, juez, alcalde, mayordomo y escribano, el almotacenazgo, con todos sus derechos; una tienda de aceite; una caballería de cada cabalgada; y, su parte en las caloñas. La concesión de exenciones fiscales comprende la del diezmo real para las heredades de los eclesiásticos, la cual se hace extensible también a las heredades de los caballeros, quiénes fueron franqueados de toda renta real; tampoco debian abonarlo los peones que fueran vecinos de Córdoba. Por lo que respecta al portazgo, estaban libres de su pago los cristianos cautivos asi como los vecinos y moradores, que estaban exentos en la ciudad y término. Ningún judío podía tener mando sobre cristianos, a excepción de si se trataba del almojarife.

El rey conserva la propiedad de cierto número de tiendas en la ciudad, pero a diferencia de lo ocurrido en Sevilla, no le pertenecen todas. Además se reserva el monarca la facultad de obligar a los artesanos a alquilar las tiendas del realengo en primer lugar; una vez ocupadas las cuales podía hacerse con aquellas otras que habra concedido a los caballeros de la ciudad. Se exceptúa de esta obligación a aquellos artesanos más apreciados por la clase dirigente, que podran alquilar tiendas a voluntad; se trata de los oficios relacionados directamente con la preeminencia social de dicha clase, con su principal actividad y funcion: la guerra; asi como con su signo de distinción estética: la ropa y el vestido. De este modo se cita entre estos artesanos privilegiados a los armeros, fabricantes de brisones, escudos y sillas; lorigueros; sastres y pellejeros, confeccionadores de vestidos y $\mathrm{p}$ rendas de piel.

\footnotetext{
${ }^{27}$ Procisamente fue el dia cuatro de abril, como consta en algunas transcripciones en castellano (Franciso CASAL, El Fuero de Córdoba concedido a la ciudad de Cartagena, Cartagena, 1971, p. 38) y en latín (Nicolás ACERO Y ABAD, Historia de la mury noble y mury leal villa de Mula, Murcia, 1886, p. 232); aunque en otras la fecha dada es la del día ocho de ese mismo mes y año [Maria del Carmen GARCIA ROMERo DE LA MONTAÑA, Estudio comparafivo de dos fueros: Alicante-Córdobo, "Revista del Instituto de Estudios Alicantinos", 10 (1973), p. 49]. Pare un eatudio del fuero de Córdoba y su edición latina, vid. Miguel Angel ORTZZ BELMONTE, El Fuero de Córdoba y las clases sociales en la ciudad de Córdoba, "Boletín de la Real Academis de Córdoba", XV, 70 (195)4; para la edición romance, vid. Privilegios reales y viejos documensos, IX, Cóndoba, $n^{0} 1$.
} 


\section{El fuero de Sevilla}

Después que Córdoba, Fernando III conquistó Sevilla, a la que en 1250 también otorgo el fuero de Toledo ${ }^{23}$. Veamos que alusiones relativas a la actividad artesanal se contienen en el que pas 6 ahora a denominarse "fuero de Sevilla":

Existe un barrio de Francos, como el que hubiera en Toledo. Este se caracteriza porque en sus casas se podía vender libre y francamente paños y otras mercaderfas, al por mayor, al detalle o por varas; asimismo se instalo alli a los pellejeros y sastres, como en Toledo; los vecinos de este barrio podían tener cambios de moneda en sus casas, mientras que no tenían obligación de guardar Alcázar ni Alcaicería, así como tampoco de pagar empréstitos reales por la fuerza; teniendo la misma consideración de la que gozaban los caballeros, según el fuero de Toledo; aunque si debran como éstos hacer hueste. Los marinos tenían un alcalde propio, en su barrio, que los juzgaba en lo tocante a asuntos del mar, a excepción de lo perteneciente al fuero de tierra; se les concedio que pudieran comprar y vender en sus casas paños y otras mercancías, al por mayor, al detalle o como quisieran, pero sin exenciones fiscales; igualmente se les otorgo 20 carpinteros, "que labren vuestros navíos y vuestro barrio", a la vez que 3 herreros y 3 alfajemes; gozaban también de honra de caballeros, según el fuero de Toledo, por lo que habian de hacer tres meses de hueste por mar; el barrio contaba además con una carnicería propia, de la cual el rey retenfa su derecho.

En el capitulo de las exenciones fiscales, aparte de las especiales concedidas al barrio de francos y al de marinos, no existen otras. En Sevilla, todos los vecinos y moradores (se cita expresamente a caballeros, mercaderes

\footnotetext{
${ }^{28}$ En Sevilla, 15-Vl-1250. Para una transcripción de dicho privilegio de concesión, vid. Manuel de BURRIEI, Memorias del rey Femando III, Barcelona, 1974, p. 144 y s. El hecho de que el fuero de Sevilla se concediese a Murcia, ha posibilitado la conservación en esta última de abundante documentación sevillana, en algunos casos aún habiéndose perdido el original. Así por ejemplo estŕ el caso de un traslado del propio fuero de Toledo concedido a Sevilla, que aunque coincide con el original en cuanto a día y mes su fecha es de un año más tarde (Archivo Municipal de Murcia [en adelante AMM], serie 3, Libro [en adelante Lib.] 1, fols. 32v-32r; y Lib. 38, fols. 6v-9r); también existe una transcripción, confimación y ampliación concedida por Alfonso X (Sevilla, 6-XIl-1253; Lib. 1, fols. 35v-39v; y Lib. 38, fols. 9r-14r).
} 
y marinos) debran dar el diezmo del Aljarafe y del Figueral ${ }^{29}$. También debran pagar los vecinos los derechos pertenecientes a la iglesia, en razon de pan, vino, ganado y otras cosas por las que se pagaba en Toledo.

Como se puede comprobar de la comparación entre los fueros de Córdoba y Sevilla, ambos no mantienen más que una lejana similitud, siendo mucho más ventajoso el derecho cordobés, al resultar ésta una ciudad menos atractiva para los repobladores.

\section{OTROS FUEROS}

La base de todo el ordenamiento jurídico murciano estuvo en los fueros derivados de Cuenca y Toledo, sin embargo en algún momento otros ordenamientos tuvieron alguna relativa presencia, más que nada testimonial.

El Fuero Juzgo, como tal, no se concedió a ninguna villa murciana; sin embargo, como dijimos, constituyo la esencia del derecho toledano, siendo utilizado en materia penal y procesal. Se trata de un código amplio al que recurrir en caso de duda en lo relativo a cada ordenamiento jurídico local. Asf por ejemplo, la ciudad de Murcia aparte de solicitar en diversas ocasiones ayuda a Sevilla, para aclarar circunstancias confusas, también pudo acudir a un ejemplar del Fuero Juzgo regalado personalmente por Alfonso $X, y$ que hoy constituye una de las mejores copias conservadas ${ }^{30}$.

Por lo que respecta al Fuero Real, éste tampoco contiene ningún tipo de referencia explícita a la actividad artesanal, como en el caso anterior; y aún su importancia en el reino de Murcia fue bastante mínima. En contra de lo que se ha afirmado, el Fuero Real parece que no se aplico nunca en la ciudad de Murcia, a pesar del mal conocimiento que en principio se tuviera del derecho sevillano; esto último motivó el enfrentamiento entre concejo y cabildo catedralicio acerca de la percepción de derechos, lo que indujo a

\footnotetext{
${ }^{29}$ Aunque en el texto transcrito por Burriel (cit., p. 166) se lee: "que non den diezmo", debiendo decir: "Que nos den diezmo", tal y como se transcribe en los documentos murcianos (Lib. 1, fol. 34v) y como se desprende del sentido del contexto de la propia transcripción del fuero, al perseguirse a quién dernandase mayor cantidad que este diezmo, siendo ésta parte de las rentas pertenecientes al almojarifazgo real (J.D. GONZALLZ ARCE, El almojarifazgo de Sevilla. Una renta feudal, "VI Coloquio Intemacional de historia Medieval Andaluza", Málaga, 1991.

${ }^{30}$ Fuero Juzgo, códice murciano (Lib. 53). Contiene disposiciones relativas a compras y ventas, así como a los juicios de los mercaderes de ultrapuertos (lib. IX); pero no contiene referencia alguna, de forme explícita, a la actividad artesanal.
} 
Sancho IV a ordenar en varias ocasiones el envio de nuevos traslados del ordenamiento sevillano, o que acudiesen procuradores de ambas partes a Sevilla para aclarar sus pareceres. Si Alfonso X no concedio el Fuero Real a Murcia, por lo que se desprende de sus vestigios en la ciudad, si que pudo estar a punto de hacerlo a Alicante, lo que hubiese constituido una excepción, al no existir otras sustituciones conocidas del Fuero Juzgo por el Fuero Real. En otras villas del norte del reino sf tuvo cierta presencia ${ }^{31}$, pero de poca importancia o duración, debido al fracaso en el intento de su implantación por parte de Alfonso $\mathrm{X}$.

Algunas alusiones nos hablan de un último tipo de fuero, al que se denomina Fuero de las Leyes, que al parecer fuera otorgado por D. Juan Manuel a sus villas del Señorío de Villena, del que nada más sabemos con certeza $^{32}$.

\section{LA ORDENACIÓN FORAL DEL REINO DE MURCIA}

Esta se enmarca dentro del programa iniciado por Fernando III, y continuado por Alfonso X, de uniformización juridica de los nuevos territorios incorporados a la corona. Se trataba, como se dijo, de unificar los derechos locales de las nuevas ciudades y villas ocupadas, a través de la concesión de ordenamientos forales pertenecientes a una misma familia. De este modo, el derecho conquense se aplico, preferentemente, a las villas fronterizas del norte del reino, más difíciles de repoblar; y, más tarde, aunque desvirtuado, a numerosos territorios de señorí, pertenecientes sobre todo a ordenes militares. El derecho toledano, variante del Fuero Juzgo, y a través de los modelos sevillano y cordobés, fue el mayoritariamente aplicado en el reino, sobre todo en las villas de mayor importancia.

\footnotetext{
${ }^{31}$ J. TORRES FONTES, El estatuto" cit., p. XXXIII. M. PESET REG, La dualidad de fueros en el Marquesado de Villena en época de don Juan Manuel, "Congreso de Historia del Señorio de Villena", Albacete, 1987, p. 298; y, Los fueros y privilegios alicantinos de Alfonso X, "España y Europa" cil., p. 737. A. PÉREZ MARTIN, El fuero Real y Murcia, "AHDE", 54 (1984).

${ }^{32}$ Tenemos el caso por ejemplo de Chinchilla, para la cual en una confirmación de sus privilegios concedida por Juan II podemos leer: "... en que me enbiaron pedir por merced que les confirmase el fuero de las leyes que han (...) e del ynfante don Manuel e don Johan su fijo..." [Juan ABEUUN PEREZ y Manuel ESPINAR MORENO, Privilegios, mercedes, libertades, ..., otorgados por los reyes de Castilla a la ciudad de Chinchilla [1266-1439] "Al-Basit", 9 (1981), p. 168].
} 
También hablaremos del fallido intento de introducción de una normativa más restrictiva, en la que la monarquía jugaba un mayor protagonismo y que destacaba por estar dotada de mayor modernidad jurídica, al incorporar el derecho romano frente a la componente consuetudinaria y gótica. Se trató del intento de sustitución de los fueros conquenses por el recién creado Fuero Real; que Alfonso $\mathrm{X}$ incluso hubiera querido introducir en lugar del propio Fuero juzgo y sus derivados.

En teorfa los fueros contenfan la trasmisión integra del primitivo derecho originario; sin embargo, dicha trasmisión ni fue integral ni igual en todos los casos; apreciándose diferencias ya entre los fueros de Córdoba y Sevilla, o entre los de Cuenca y Alcaraz. También de forma teórica, junto al fuero propiamente dicho, las villas acogidas a un determinado derecho local habrian de recibir además su normativa complementaria (privilegios, normas, leyes, ordenanzas, ...); y recurrirían al texto del fuero amplio (Fuero Juzgo, Fuero de Cuenca) como código complementario en materia juridica, penal y procesal. Pero, los fueros otorgados a las villas murcianas no suelen reproducir integras las disposiciones forales de las villas matriz. Se habrá de considerar, por tanto, que se otorgo sólo aquella normativa contenida en la carta-privilegio de concesión. Tampoco hubo un traspaso inherente del derecho complementario, sino que por el contrario, cada villa tenfa el suyo propio directamente concedido por el respectivo monarca o señor. Las excepciones a esta circunstancia pueden ser la ciudad de Murcia, atenta siempre al continuo trasvase jurídico con Sevilla, u otras villas del reino que intercambiaron entre si fueros y franquezas (esto es, el fuero más el conjunto de privilegios recibidos hasta la fecha del intercambio), sin que se hiciese con la correspondiente villa matriz. Tampoco abundan las referencias a las posibles consultas del fuero amplio, como código complementario.

Veamos cuál fue la estructuración foral del reino de Murcia, y si ésta atendio a algún plan preconcebido:

-Los fueros de la familia conquense fueron concedidos a las villas de: Almansa $(1262-12624)^{33}$ y Chinchilla $(1269)^{34} ; y$ también, en su ver-

\footnotetext{
33. CERDA, Fueros municipales a ciudades del reino de Murcia duranse el siglo XIII (12451283), "MMM", XIII (1987), p. 184. Almansa recibió el fuero de Cuenca en 1262, a través de Requena; exta, a su vez, recibió el Fuero Real en 1264, reiterándosele a Almansa el Fuero de Cuenca; lin cual, en 1265 recibía ahora el llamado "fuero nuevo de Cuenca", con las franquezas de Alicante (M. PESET, Los fueros y privilegios cit., p. 747); según Juan Torres Fontes, el "fuero nuevo" lo rocibió en 1264 (Evolución del concejo cit., p. 12).
} 
sion señorial, a diversas localidades santiaguistas, como Caravaca (1286) ${ }^{35}$, Cehegín, Bullas y la villa de Segura ${ }^{36}$, a través del fuero de Alcaraz ${ }^{37}$, concedido a Caravaca y de ahi a sus aldeas de Cehegin y Bullas ${ }^{38}$; y a Yeste y Taibilla ${ }^{39}$, entre otras.

-Los fueros de la familia toledana los podemos dividir en tres grupos:

a) El fuero de Toledo. Es con mucho el menos aplicado en Murcia, otorgado parcialmente y con casi nula repercusión artesanal. Lo recibieror solo Alicante (1257), Cartagena (1257) y Orihuela $(1282)^{40}$.

b) El fuero de Córdoba se concede a: Mula (1245), Cartagena (1246) y Alicante $(1252)^{41}$, habiéndolo recibido esta última a través de Cartage$\mathrm{na}^{42}$. El fuero de Alicante, a su vez, se aplicó en Almansa, posiblemente en 1257-125843, aunque la fecha más probable fuera la de $1265^{44}$; y también en Orihuela $(1265)^{45}$. Aunque pudiera haberse concedido el fuero de Alicante a Lorca, no hay pruebas de ello ${ }^{46}$, y por tanto no se puede hacer derivar los fueros de Lorca, Yecla, Villena o Aledo del de Alicante ${ }^{47}$;

\footnotetext{
${ }^{34}$ El fuero de Cuenca, a través de Alarcón, fue el concedido a Chinchilla (M. PESET, La dualidad, cit., p. 300: y, Los fueros de la frontera, cit., p. 40); resulta curioso que casi ningún autor recoja esta concesión.

35J. CERDA, cit., p. 184.

${ }^{36}$ José María FONT RIUS, Algunos aspectos juridicos de la repoblación murciana, "Primera Sernana de Estudios Murcianos", Murcia, 1961, p. 183.

37J. TORRES FONTES, cit., p. 12.

38. CERDA, cit., p. 167.

${ }^{39} \mathrm{M}$. PESET, cit., p. 40.

${ }^{\circ} \mathrm{J}$. TORRES FONTES, cit., p. 12.

"Ibidem.

22J.M. FONT RIUS, cit., p. 183; y, M. PESET REg, Alfonso $X$ y el fuero de Alicante, "Studia Historica in Honorem Vicente Martínez Morellá", Alicante, 1985, p. 303. Por lo menos algunas de sus disposiciones sí provenian de Cartagena (J. CERDÁ, cit., p. 165).

${ }^{43}$ Según J. Cerdá (ibidern, p. 183).

4J. TORRES FONTES, cit., p. 12; y M. PESET, Los fueros y privilegios cit., p. 747.

4s Bbidem, p. 750.

${ }^{46}$ J. CERDA, cil., p. 165.

${ }^{47}$ Como lo hace J. Cerdá, (ibidem, p. 165).
} 
sino que fue directamente el fuero de Córdoba el que se concedió a Lorca, en 1271, de la cual se pasó a Villena(1276), Yecla (1280) y Aledo (1293) ${ }^{48}$.

c) El fuero de Sevilla fue concedido a Murcia en 1266, y desde Ésta a numerosos lugares de su jurisdicción ${ }^{49}$, como Mula (1267), Molina Seca (1267) y Valle de Ricote (1267) ${ }^{50}$. También desde Murcia se trasvas 6 a Orihuela $(1268)^{s_{1}}$, y conjuntamente con el de Sevilla a Elche (1267). Mas tarde recibiría el fuero de Murcia Jumilla (1357); y sus franquezas Lorca, Villena, Yecla y Aledo, en $1283^{52}$.

Evidentemente, son más numerosas que las aqur citadas las villas murcianas que, en uno u otro momento, recibieron algún fuero de las familias referidas. Sin embargo, por su poca importancia, o tardía concesión, no parecen recogidas. Cuando ello sea preciso serán aludidas más adelante, a la vez que nos detendremos en las circunstancias concretas de cada concesión y lo que ésta implicó en materia económica y artesanal. Veamos ahora que enseñanza podemos extraer de la anterior ordenación jurídica del reino de Murcia.

En el aspecto que a nosotros interesa, el artesanal, esta ordenación parece atender a claras intenciones políticas. A los territorios inseguros, por causas fronterizas, y con buena disponibilidad ganadera, se ajustó las características del fuero de Cuenca, con sus amplias garantías, libertades y franquezas en materia económica. Utilizado como herramienta repobladora, para la atracción de pobladores a zonas fronterizas, cuando las mismas perdieron este carácter el rey intentó recortar estos márgenes, que ya no se justificaban al haber avanzado la frontera; el intento fallido de introducción del Fuero Real, fue seguido por la concesión de un nuevo fuero de Cuenca, más recortado en cuanto a privilegios y franquezas; para finalmente acabar otorgando fueros y franquezas derivados del derecho toledano, que al superponerse al más ventajoso derecho conquense supusieron un recorte de este amplio marco jurídico. Similar es el caso de las villas de señorío, sobre todo 183.

${ }^{43}$ J. TORRES Fontes y A.L. MOUNA MOUNA, cit., p. 346; y, J.M. FONT RIUS, cit., p.

"Ibidem.

${ }^{50} \mathrm{~A}$ pesar de que no han quedado pruebas documentales (J. CERDÁ, cit., p. 184; y J. TORRES FONTES, cit., p. 12).

"I bidem.

52J. TORREs Fontes y A.L. Mouna Mouna, cil., p. 346. Aunque J. Cerdá apunta las fechas de 1270 y 1272 (cit., p. 184). 
las de la Orden de Santiago; las cuales, generalmente a partir del fuero de Alcaraz, recibieron un ordenamiento jurídico ya muy recortado que en poco se parecía al original. Este estaba acorde con las necesidades económicas de los señores de las encomiendas.

Los fueros de la familia toledana se ajustan mejor a las necesidades de la realeza, que pretendía atraer población con fines repobladores, pero que a su vez querfa obtener de la misma ingresos económicos en forma de rentas y exacciones. De éstos era el de Sevilla el que permitra una mayor disponibilidad para el monarca; dejándose el fuero de Córdoba, más ventajoso, para aquellas zonas que precisasen un mayor nivel de privilegios, debido a su situación fronteriza o a especiales necesidades repobladoras. No resultó tampoco infrecuente que el más ventajoso derecho cordobés fuese recortado con una posterior adición del sevillano, para localidades en las que variaron las circunstancias de su concesión.

A continuación, desarrollaremos dichos aspectos, deteniéndonos en la concreta concesión de los ordenamientos forales, que será estudiada por orden cronologico, para poder observar así el consiguiente trasvase jurídico entre las distintas villas murcianas. En primer lugar nos ocuparemos de las de realengo y más adelante de las de señorío; sin olvidar que, aunque algunas de ellas comenzaron siendo territorios de la Corona, no tardaron mucho tiempo en ser donados a algún señor u orden militar.

\section{Villas de realengo}

Las villas de realengo fueron las mayoritarias en el reino de Murcia tras su incorporación a la corona castellana. Prácticamente todas recibieron su ordenamiento foral en los primeros tiempos de esta incorporación, generalmente después del sometimiento de la sublevación mudéjar; e incluso antes, durante el periodo del protectorado y conquista de aquellas localidades que no lo aceptaron.

Precisamente fue la expedición castellana destinada a conquistar las villas de Mula, Cartagena y Alicante, que no se sometieron a la capitulación de Alcaraz, la que propició la primera concesión de fueros y la creación de los primeros concejos, según el más ventajosos derecho cordobés. En primer lugar fue Mula, que recibio, en 1245, el fuero de Córdoba, según un privilegio de concesión, en latín, otorgado por Fernando III; con traducción al castellano de 1266 , a petición del concejo de la villa; además 
de una confirmación de su hijo, Alfonso X, también en latín $n^{53}$. Entre las mercedes que se otorgaron a la villa no consta una copia del fuero, pero si que se concedía tal y como se le diera a la ciudad andaluza, más algunas ampliaciones incluidas en la carta de concesion. Se trata de la total exención de portazgo y peaje en todo el reino, a excepción de Murcia y Toledo, cuando en el fuero de Cordoba dicha exención se circunscribfa exclusivamente a la propia ciudad.

Cartagena recibirfa también el fuero de Cơrdoba un año después, en 1246. Esta concesión se explica, aparte de como en el caso anterior por la inseguridad de un reducto de población cristiana en una zona mayoritariamente musulmana, porque tanto Cartagena como Alicante iban a ser potenciadas como futuros puertos castellanos en el Mediterráneo, a través de los cuales monopolizar el tráfico comercial y la expansión bélica, cara a los competidores aragoneses y granadinos. Para ello era precisa la concesión de un marco generoso, que además hubo de ser ampliado con las correspondientes concesiones especificas al respecto ${ }^{54}$. Sin embargo, aunque el fuero de Córdoba fuese más ventajoso que el de Sevilla, carecía de las especiales disposiciones de éste relativas a la marina y los marinos, por lo que dichas ampliaciones fueron encaminadas a suplir esta ausencia.

Como para Mula, el fuero de Córdoba fue concedido a Cartagenass, "assi como lo han los de Cordoua", sin que tampoco se incluya el texto de dicho fuero. Cuyas franquezas fueron asimismo ampliadas al incluir el privilegio de concesion algunas referencias a los navios con base en Cartagena, sobre derechos, ancoraje y hueste. El rey se reserva, además, la propiedad de las salinas, asi como el diezmo de las salinas de los vecinos; también la propiedad de todas las minas, pudiendo los vecinos trabajar en ellas con el consentimiento del señor y pagando el diezmo. Aparte de estas disposiciones, que lógicamente no podfan figurar en el fuero de Cordoba, existen también algunos recortes del mismo: si el almotacenazgo cordobés, cedido por el rey a su concejo, contenía los derechos sobre pesos y medidas,

\footnotetext{
33" CODOM", III, pp. 8-9; y en N. ACERO, cit., pp. 166-169 (sitio sobre Jacn, 8-VIII1245). "CODOM", III, pp. 9-10; y, N. ACERO, cit., p. 171 y ss. (mismo lugar y focha).

4J. TORRES FONTES, Los puerlos de Cartagena y Alicante en la segunda milad del siglo XIII, Congreso di Storia della Corona d'Aragon, II, Palcnno, 1984; y, El puerto de Cartagena en la época de Alfonso XEl Sabio, "Murcia", 8, 1976.

ss" "CODOM", III, pp. 11-13; F. CASAL, cit., p. 23 y ss.; y, M. de BuRrIILl, cit., p. 483 y 8s. (sitio sobre Jaen, 16-I-1246).
} 
en Cartagena el rey retuvo todos los pesos, tanto del quintal como de la romana, aunque cedio todas las medidas al concejo; cualquier vecino podfa además tener medida en su casa, asi como peso de hasta una arroba, pero si pretendía pesar al quintal o a la romana debla pagar su derecho al señor. En las tiendas, el caso cartagenero es similar al cordobés, aunque ahora las diferencias son conducentes al aumento de las ventajas; cualquier vecino de la villa podia hacer y tener tiendas, siempre que se respetase el plazo de 15 dias para que previamente se alquilasen las reales; de hecho se dio libertad de establecimiento de las mismas para todos los vecinos, respetándose la preeminencia de las de realengo. Nada hay tampoco relativo a la obligación de los artesanos de alquilar primero las tiendas reales, algo que se supone implícito debido a dicha preeminencia, pero sin que exista discriminación en favor de algunos oficios más privilegiados por su especial servicio a la clase dirigente. En Cartagena, tanto el almotacén, como otros magistrados concejiles, debran ser puestos por los hombres buenos, vecinos de la villa; pero, a diferencia de Cordoba, el rey o "sennor" se reservaba la facultad de designarlos.

Como ocurriera para Alicante, los vecinos de Cartagena eran francos en todo el reino de Murcia, sin que se especifique de qué derechos. Dicha franqueza se presenta ambigua, y si se ha dado la explicación de que afectaba sólo a los cristianos, mientras que los mudéjares deblan pagar un $4 \%$ por el pleito que mantenfan contra el rey ${ }^{56}$. Por lo concedido a Cartagena, parece ser que los vecinos de la villa fueron franqueados del pago de portazgo en todo el reino de Murcia, sin que dicha franqueza eximiese de pagar sus derechos a los moros, que habian interpuesto un pleito a este respecto ante el rey cristiano. Hay que tener en cuenta que en teorla las comunidades mudéjares constituran un reino aparte bajo el protectorado castellano, y de lo que se exime en el fuero es de aquellos derechos pertenecientes a la corona castellana no extensibles por tanto al reino musulmán. Dicha exención tampoco afectaba a la ciudad de Murcia, en la cual se debra pagar un $4 \%$ por las mercancías all vendidas. Que la exención fuese de portazgo, se apoya en que fuera ésta la incluida en el fuero de Córdoba, con arreglo sólo al propio término concejil, que ahora por tanto se ve ampliada.

\footnotetext{
${ }^{56}$ Maria de los Llanos MARTINEZ CARRILO, Alicante durante el reinado de Alfonso $X$ El Sabio, "MMM", XIII (1986), pp. 76-77; y sobre todo, La sociedad alicantina en la segunda mitad del siglo XIII. La organización de Alfonso X El Sabio, "Studia Historica in Honorem" op. cit., p. 236).
} 
Ora explicación para esta ambigua reglamentación se centra el término "pleito", el cual interpuesto por los mudéjares ante el rey se puede entender en otro sentido, como pleitesía o vasallaje, por los que los musulmanes se sometían a la Corona castellana, como reino vasallo; gracias a esta sumisión se les concedio, como reino, la posibilidad de proseguir percibiendo rentas, e incluso de cobrarlas a los cristianos. Esta teorla se ve reforzada si nos remitimos a lo ocurrido en Sevilla, donde también según su arancel de portazgo, todos aquellos moros que "se aforraren y pleitearen darán el diezmo"; esto es, aquellos mudéjares acogidos al fuero y que rindieran vasallaje debian diezmar al monarca. Si este vasallaje, "pleyteamiento" o "sseruimiento" duraba años, se podía excluir del diezmo lo relativo a la manutención y vestido de los mudéjares; aquellos que estuviese aforados, si querían partir a tierra de moros debran de pagar, además del diezmo, un maravedí de salida; estando exentos los niños de pechos?.

El caso de Alicante es muy similar en algunos aspectos al anterior. En 1252 Alfonso X concedía a la villa tanto el fuero de Córdoba como el de Cartagena, así como las franquezas de esta última. El privilegio de concesión contenía la copia de ambos fueros, con algunas diferencias, así como algunas mercedes adicionales ${ }^{58}$. Aunque no se conserva el original del fuero, si han quedado varias copias ${ }^{59}$, de las que utilizaremos la existente en el Archivo Municipal de Alicante ${ }^{60}$ para su estudio.

Comienza el texto alicantino como el cordobés, con la exención del diezmo real sobre las heredades, de toda real pecha y agravamiento ${ }^{61}$; y aunque Alicante contase además con las franquezas de Cartagena, manifiestas son las diferencias con esta última. En la elección de almotacén, como de los restantes magistrados urbanos, ya ni siquiera intervienen los hombres buenos

\footnotetext{
"7J.D. GONZÁLEZ ARCE, Cuaderno de ordenanzas, y otros documentos sevillanos, del reinado de Alfonso X, "Historia. Instituciones. Documentos", 16 (1989), doc. IV.

S"M. PESET, Alfonso X cit., p. 308. Para una tranacripción de dicho privilegio, "CODOM", III, pp. 16-20; y M.C. GARCtA ROMERO, cit., pp. $36-42$ (Sevilla, 5-X-1252).

${ }^{99} \mathrm{Para}$ un seguimiento de las cuales vid., M. PESET, Los fueros y privilegios alicantinos cit., p. 228 y 88.

${ }^{\infty}$ "CODOM", III, Pp. 16-20.

61J. Cerdá incluye en la exención el pago del portazgo, que no se cita expresamente (Reflexiones sobre el derecho y sociedad en el fuero de Alicante. "Studia Historica in Honorem", op. cit., p. 63). Tratándose más de una liberación de cargas sobre la tierra que de una exención de impuestos (M. PESET, Los fueros y privilegios cit., p. 745).
} 
de la villa, sino que son directamente designados por el rey ${ }^{62}$. Esta desviación de la letra del fuero de Córdoba significó que, aunque el rey quiso reservarse la facultad de elegir las autoridades locales, les entrego el más amplio y ventajoso derecho cordobés con que compensar esta anormal facultad real ${ }^{63}$. Dichos funcionarios, incluido el almotacén, debfan ser vecinos de la villa, pero en ningún momento se cede a su concejo el almotacenazgo con sus rentas ni la tienda del aceite, como se ha dado a entender ${ }^{64}$; lo máximo que obtuvo, recordándole al rey que se estaba aforado a Cartagena, fue que en 1256 el monarca le permitiera elegir a su almotacén y otros funcionarios; esto es, que se hiciese a consejo de hombres buenos, pero con el beneplácito real. A este respecto el rey dispuso que tanto el almotacén como los otros funcionarios debfan ser hombres buenos, tales que le pudieran prestar a él servicio y bien a la villa ${ }^{65}$. Recuérdese que ello implicaba que se reservaba estos cargos para una minoría privilegiada.

Como en Córdoba, ningún vecino de Alicante podra estar bajo mando de ningún judío o converso, a excepción de si era almojarife. También, como en dicha ciudad, se concedió a los vecinos y moradores exención de portazgo, en Alicante y su término; pero no en todo el reino, como serfa el caso de Cartagena. En lo relativo a las tiendas y a la propiedad inmueble se dio una pequeña variante con respecto a Córdoba, al quedar prohibido que armeros, alfayates o pellejeros pudieran alquilar tiendas reales, cuando alli era opcional. Pero, como en Cartagena, cualquier vecino podía tener tiendas propias, preservándose los derechos reales.

La concesión del fuero y franquezas de Cartagena a Alicante no implicaba el automático trasvase de todo el derecho local de la primera a la segunda, sino sólo de aquellos extremos explícitamente concretados. Así, para que el desarrollo de ambos puertos corriera parejo, 20 días después de dicha concesión ésta era completada con la de los privilegios otorgados a Cartagena, recogidos ahora de forma detallada ${ }^{66}$. Se trata de las disposiciones relativas a salinas, minas, pesos, medidas, tiendas; asf como la

\footnotetext{
${ }^{62}$ Ibidem, Pp. 735-736; M.C. GARClA ROMERO, cit., p. 26; y, "CODOM", III, p. 16. Para un estudio comparado de los tres fueros, J. CERDÁ, Fueros municipales cit., p. 170.

${ }^{63} \mathrm{M}$. PESET, Alfonso X cit., p. 319.

${ }^{4}$ Como lo hace M.C. GARCLA ROMERO, (cit., p. 34). 1256).

${ }^{65}$ M. PESET, cit., p. 320; y Los fueros cit., p. 743. "CODOM", IIl, p. 34 (Vitoria, 15-I-

66"CODOM", III, Pp. $21-23$ (Sevilla, 25-X-1252).
} 
franqueza en Alicante, y todo el reino de Murcia, a excepción de lo debido a los moros y del $4 \%$ a pagar en la capital.

Incluso meses antes que a la propia Cartagena, Alfonso X habla concedido a los hidalgos, burgueses, marineros y ballesteros de Alicante las franquezas y fuero de los hidalgos de Toledo ${ }^{67}$.

La villa de Almansa estuvo en un principio aforada al derecho conquense, a través de Requena, de la que recibió su fuero y franquezas; entre las que destaca la exención de portazgo en Moya, Cuenca, Huete, Alarcón, Jorquera, Ves, Ayora y Chinchillab. El texto de concesion no recoge el contenido del fuero de Requena, ni mucho menos el de Cuenca. Desconocemos pues la amplitud de su aplicación en la villa, que debió ser poca, cuando el fuero de Cuenca contaba con exención general de portazgo y a la villa sólo se le concedió en otras vecinas. Cuando Requena recibió el Fuero Real, en 1264, se reitero a Almansa el suyo de Cuenca. En el texto de esta confirmación tampoco se contienen referencias forales ni otros privilegios que nos interesen. El cambio estuvo ocasionado porque, mientras que Requena habla dejado de ser una villa fronteriza, no fue asi con Almansa, a la cual se querf́a atraer poblacion ${ }^{69}$. Finalmente, en 1265 se le concedía a Almansa el fuero nuevo de Cuenca y las franquezas de Alicante. Tampoco este privilegio ofrece explicaciones textuales de los IImites de dicha concesión, ni aún sabemos lo que representaba el "fuero nuevo de Cuenca". Pudo tratarse de una aplicación conjunta del fuero de Cuenca, Fuero Juzgo y las franquezas alicantinas; otra hipótesis apunta a que se trato de los privilegios concedidos a Cuenca a partir del reinado de Fernando III y Alfonso X, a los que desde 1268 se les comenzo a denominar "fuero nuevo"; de manera que en la lucha de Alfonso $X$ contra la vigencia del derecho conquense a las villas murcianas se les otorgarfa sólo dichos privilegios, más restrictivos, y no asi el antiguo texto foral Integro. Parece descartada la posibilidad de que

\footnotetext{
"7"CODOM", III, p. 40 (Alicante, 12-I-1257). A Cartagena también se concedió el fuero de Tolodo, ibldem, 53-55 (Monteagudo, 6-V-1257).

".CODOM", III, p. 79 (Seville, 15-IV-1262); Vid. A. PRETEl MARIN, Almanso medieval, una ville del seftorlo de Villena en los siglos XIII, XVV y XV. Albecete, 1981, p. 25. Requena habia rocibido en 1257 el fuero de Cuenca (A. PRETzl, Conquista, cit., pp. 268-270; Atienza, 4-VIII-1257).

"A. Pretel, Almansa, cit., pp. 181-182; y "CODOM", III, p. 82 (Sevilla, 9-X-1264); M. PESET, Los fueros y privilegios, cil., p. 747.
} 
el "fuero nuevo" fuese en realidad una nueva redacción del primitivo fuero de Cuenca ${ }^{\text {To }}$.

En cualquier caso, lo que si parece quedar claro es que Almansa nunca contó con la total vigencia del derecho de Cuenca. Bien sea porque sólo podamos considerar que se le concedieron aquellos aspectos que se citan explícitamente. Bien porque sólo se dio una aplicación parcial, el llamado "fuero nuevo". Pero sobre todo, porque lo que en realidad ocurrio fue una sustitución del más ventajoso derecho conquense por el más restrictivo marco cordobés, a través del fuero de Alicante y sus franquezas. El asunto a nivel economico queda reducido al estudio de las disposiciones alicantinas que se aplicaron en Almansa, pues no sólo desconocemos las contenidas en al anterior marco jurídico, sino que éstas últimas fueron las únicas en llevarse a la práctica. Se trata de una pirueta legal, empleada en otros casos dentro del reino de Murcia, según la cual la adición de un derecho más restrictivo no significa la suma de ambos, sino que se aplicaron en cada caso aquellas fórmulas más interesantes para el poder político; en este caso las contenidas en el derecho alicantino ${ }^{71}$.

De haber tenido plena vigencia el derecho conquense, en materia artesanal la introducción del alicantino habría supuesto un giro copernicano, dada la manifiesta disparidad de ambos textos. En materia fiscal se paso de una teórica exención general a parciales exenciones de portazgo y diezmo, según lugares y categorfas sociales. A la libre disponibilidad de los medios de producción, en poder de los vecinos, siguió la preeminencia de las tiendas reales. La libertad de pesos y medidas ahora se ve mermada en beneficio de monopolios reales y concejiles. El almotacén paso a ser un funcionario elegido por el rey.

Además, junto al fuero alicantino, la concesión a Almansa inclufa las franquezas otorgadas a Alicante. Esto es, el conjunto de privilegios y normativa real otorgada a la ciudad hasta 1265 , fecha de su trasvase a

"ToDOM", III, pp. 83-85; y A. PreTEL, cit., p. 257 y s8. (Sevilla, 15-II-1265). M. PESET, cil., pp. 247-248.

"Lejos de encontramos frente a la suma de las ventajas contenidas en el fuero de Requena, el fuero nuevo de Cuenca y en el de Alicante (Como sugiere A. PRETEL, cit., p. 28); se trata en realidad de un simple sustitución del más ventajoso derecho de Cuenca por el má restrictivo Fuero Juzgo, según la política real de aumento de control sobre los territorios que ven alejarse la frontera, sobre los que podian pues aumentarse las exacciones (M. PESET, cit., p. 40); sin que ello significase un gran impedimento para el desarrollo de la villa (A. PRETEI, Conquista, cit., p. 192). 
Almansa. Sin embargo no todos ellos se aplicaron en esta villa, sino sólo una selección acorde con sus necesidades y con los deseos reales, que nos es conocida gracias a la posterior y sucesiva confirmación de estos privile$\operatorname{gios}^{n}$.

Parece ser que la villa de Orihuela pidió ella misma la concesión del fuero de Alicante, en 1265. Petición que fue atendida al ser adecuado para la oligarquía local as como para la propia corona. Sin embargo, no obtuvo la documentación de dicha concesión hasta 1271, por lo que mientras tanto debieron existir algunas copias particulares. Dicha concesión debió de producirse hacia el 25 de agosto de dicho año 1265. cuando el rey otorgaba a Orihuela y sus pobladores las mismas franquezas, privilegios, gracias y mercedes que había dado el mismo Alfonso $X$ a la villa y pobladores de Alicante ${ }^{n}$. Como para Almansa, en ninguna de las dos cartas de privilegio mediante las cuales se concedía el fuero y privilegios de alicantinos a Orihuela se copio dicho fuero ni se especificaron las franquezas; simplemente se señala que se conceden éstos, "que lo ayan como el conçeijo de Alicant lo han". Lo que tampoco se hizo cuando en 1273 el propio rey confirmaba sus fueros y privilegios a Orihuela ${ }^{74}$.

Murcia recibió el fuero de Sevilla, junto con otras mercedes, en 1266. Se explica la concesión de un fuero menos ventajoso que el de Córdoba porque la capital precisaba una menor concesión de libertades a la hora de atraer repobladores. Tampoco aqui se incluye una transcripción del fuero sevillano, motivo por el cual Sancho IV ordenó al concejo de Sevilla facilitar un traslado de su fuero al de Murcia"s; dentro del continuo tráfico documental establecido con el fin de aclarar y ordenar el derecho local murciano, con arreglo a los preceptos sevillanos.

Aparte de conceder el fuero de Sevilla, "assi como ellos lo han", el privilegio ofrece algunas novedades en materia artesanal: el rey retenfa dentro de las rentas pertenecientes al señorío regio, portazgos, molinos,

\footnotetext{
${ }^{2}$ La última de las cuales corresponde al reinado de los Reyes Católicos, en el año 1476 (A. PRETEL, Almansa, cil., pp. 242-266).

${ }^{73} \mathrm{M}$. PESET, Los fueros y privilegios, cit., p. 750. Juan Manuel del ESTAL, Documentos inéditos de Alfonso X El Sabio y del Infanse, su hijo don Sancho, Alicante, 1984, p. 236. Y, Juan Bautista VILAR, Historia de la ciudad de Horihuela. Il Orihuela Musulmana, Orihuela, 1980, pp. 246-247.

"A"CODOM", III, pp. 115-116 Y 120-121 (Murcia, 20-VII-1271). Ibidem, pp. 145-146 (Guadalajare, 4-VII-1273).

75"CODOM", I, pp. 17-21 (Sevilla, 14-V-1266). "CODOM", IV, p. 54 (Madrid, 5-I-1286).
} 
aceñas, hornos, baños, alcaicerías, alhondigas, almacenes, tiendas, pesos, medidas, mercados, las calderas de teñir paños y la tienda de la sal. Rentas estas incluidas dentro del almojarifazgo, y que, aunque no se especifiquen propiamente dentro del texto del fuero de Sevilla, sí están recogidos en su derecho local y se aplicaron en esta ciudad ${ }^{76}$.

Por lo que sabemos de Sevilla, tal y como consta en las franquezas contenidas en el privilegio de concesión de su fuero a Murcia, la propiedad de los inmuebles productivos configuró un monopolio real, y las rentas derivadas del mismo se inclufan en su respectivo almojarifazgo. Al cual pertenecian, no sólo los derechos por la utilización y uso por parte de los vecinos de los molinos, aceñas, hornos, etc.; sino también las rentas que éstos debran pagar por la apertura de tiendas. Posibilidad que les ofreció el rey una vez que, como ocurría en Córdoba, se hubiera previamente arrendado las tiendas reales. La diferencia estriba en que los pobladores aforados a Sevilla pagaban rentas al monarca por sus tiendas, no asf los que lo estaban a Cordoba, donde existe cierta capacidad de propiedad libre.

Si el panorama inmobiliario de Murcia se presenta similar al de Sevilla, no corre as 1 con otros aspectos del fuero. La ciudad nunca contó con un barrio de francos, como Sevilla o Toledo, ni con las especiales facilidades de éste en materia comercial y artesanal. Y, evidentemente, tampoco con un barrio de marinos, igualmente excepcionalmente privilegiado. Motivo este que no permite comparación alguna entre las tiendas francas de ambos barrios con la posibilidad que se ofrece a los vecinos de Murcia de abrir tiendas en sus casas, cuando en éstas no sólo no existía venta franqueada sino que además debran pagar una renta real por su apretura ${ }^{n}$.

A pesar de lo cual, y tal vez como compensación, con el fuero se concedio a la ciudad exención de portazgo, as como de otros derechos pagaderos en la puerta y mercados de la villa. Esta era sólo aplicable a los vecinos, no asi a los forasteros, de aquello que sacaren o metiesen; exención similar a la contenida en el derecho cordobés. Y, frente a lo que ocurrió en Cartagena y Alicante, en Murcia desde el principio su concejo tuvo la facultad de elegir al almotacén, a consejo del representante real. Pero,

${ }^{76}$ J.D. GONZÁLEZ ARCE, Señorio regio e implantación de la producción textil en la Murcia del siglo XIII (I), "MMM", XIV, (1987-1988), p. 184; Señorio (y 2), "MMM", XV (1989), p. 106; y, El almojarifazgo, cit.

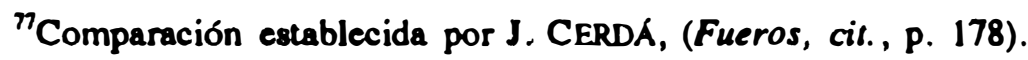


también a diferencia de ambas ciudades, el rey mantuvo el monopolio sobre los pesos y las medidas ${ }^{n}$.

La concesión del fuero y franquezas de Murcia a Orihuela ${ }^{\text {t9 }}$, en posesión del, a priori, más ventajoso derecho alicantino, no supuso en esta ocasión restricción alguna, por la aplicación complementaria de algunos de los numerosos privilegios con los que hasta la fecha contara Murcia, que tuvieron cierta difusión, como veremos, en la villa. Ello explicaría la poca resistencia de la oligarquía local, que sin embargo contestó reclamando copias, hasta ese momento inexistentes, del fuero alicantino. La ambigüedad jurídica que se tuvo que producir con la vigencia de dos ordenamientos forales, fue aprovechada por los funcionarios reales para aplicar en cada caso aquel derecho mas interesante a las necesidades de la corona, y que sin embargo no tenían por qué resultar lesivas para la oligarquía local, sino en todo caso para la clase productora.

La aplicacion del ventajoso fuero de Cuenca en Chinchilla parece reducirse, a una mera exención de algunas exacciones. Ello se explica por su tardía concesión, 1269, que se hizo a través de su derivación de Alar$c o n^{20}$. En el escueto privilegio sólo se dice que se otorgaba el "fuero de Alarcon conplidamientre en todas cosas". En este momento la villa atravesaba por una crítica situación, que explica la tardía concesión de un fuero de esta rama en claro retroceso.

Fue Lorca la villa, de entre las de importancia, que más tardfamente recibio el fuero de Córdoba. Esto ocurría en $1271^{81}$. Existen sin embargo posibilidades de que le hubiese sido concedido con anterioridad por Fernando III, tal y como consta en el privilegio de la que asi sería su nueva

\footnotetext{
Murcia obtuvo la exención de portazgo porque previamente se le concediera a Sevilla, primero parcinlmente, pare los libros llevados a su "Studium" de latín y árabe (Antonio BALUesteros BereItA, Sevilla en el siglo XIII, Madrid, 1913, doc. 67; en Burgos, 28-XII1254), y dos años mós tande de forma general, con exención en la ciudad para todos sus vecinos (Memorial Histórico Espantol, I, pp. 82-83; en Vitoria, 23-I-1256); para agradecer la magnificencia real, el concejo donó al cabildo catedralicio $100 \mathrm{mrs}$. anuales, de la renta del portazgo, con la finalidad de que se organizase una procesión en honor de Alfonso X (A. BNUESTEROS, cit., doc. 91; en Sevilla, 17-VIl-1257).

${ }^{79}$ "CODOM", III, p. 97 (Jerez, 4-III-1268).

${ }^{\infty}$ A. PreTEl, Conquista, cil., pp. 276-277 (Jaen, 8-III-1269).

"Francisco CANOVAS Y COBENO, Historia de la ciudad de Lorca, Lorca, 1980, pp. 195. 204; J. TORRES FONTES, Repartimienso de Lorca, Murcia, 1977, pp. 76-84; y "CODOM", III, pp. 123-131 (Murcia, 20-Vill-1271).
} 
concesion $^{22}$. En este caso el privilegio lorquino si es de los que reproducen el texto más o menos integro del fuero otorgado, por lo que resulta sencillo su cotejo con el derecho matriz. A Lorca, como insegura villa fronteriza se le respetó bastante la vigencia del derecho cordobés. Asf, a diferencia de Cartagena o Alicante, el almotacenazgo y sus derechos, con las tiendas del aceite, pertenecieron desde el principio al concejo. Lo mismo ocurre con la prohibición de que los judíos pudiesen tener mando sobre cristianos, a excepción de si eran almojarifes; con la exención del diezmo real y con la de portazgo en el término de la villa; o con lo relativo a las tiendas y los menestrales que debran alquilarlas.

Para terminar este apartado, referiremos las restantes villas de realengo que obtuvieron fueros de la realeza, pero en las que no nos detendremos por su escaso interés: Albacete, parece que fue concedida, por Fernando III, como aldea de la villa de Alarcón ${ }^{83}$. Fue alfonso $X$ quién concediera el villazgo, con términos y fuero de Cuenca, a Ves ${ }^{24}$. Sancho IV, todavía infante, concedfa el fuero de Toledo a Orihuela, a su clase dirigente ${ }^{85}$; y una vez rey, el de Alcaraz a Caravaca, y como aldeas Cehegin y Bullas ${ }^{86}$; que pronto pasarfan a ser de señorío y sobre las que luego volveremos. Tardfamente, Jumilla, tras ser reconquistada para Castilla por Pedro I, y reintegrada al realengo, obtuvo el fuero y franquezas de Mur$\mathrm{cia}^{87}$.

Hacia finales del siglo XIII, o principios del XIV, podemos considerar finalizada la actividad normativa en materia de concesiones forales; al menos por lo que respecta a las villas de realengo en el reino de Murcia. Por el contrario, hasta bien entrado el siglo XV, e incluso después, en tierras de señorío continuaron entregándose fueros y cartas-pueblas, con finalidad

ڤ. CERDA, Principios, cit., p. 707.

"Biblioteca Nacional (Investigadores) 13124-Dd-146; Madrid, 1241.

A. PRETEl, cir., pp. 279-280 (Murcia, 22-11-1272).

"S"CODOM", IV, p. 31 (Toledo, 4-V-1282).

${ }^{26} \mathrm{~J}$. TORRES FONTES, Documentos para la historia medieval de Cehegin, Murcia, 1982, p. 87 y 8s. (Salamanca, 14-1-1286).

"Asociación de Amigos de Jumilla: Reales privilegios, exenciones y franquezas concedidos a la M. N. y M. L. villa de Jumilla, "Cuademos culturales", 1, Murcia, 1980, pp. 20-23 (Sevilla, 20-X-1357). Concesión confirmada por sucesivos monarcas (ibidem, p. 23 y 8s.), como consta en una confirmación de los Reyes Católicos (AMM, Cartulario Real 1494-1505, fols. 263r-266r; y Archivo Histórico Provincial de Albacete [en adelante AHPA], Sec. VII, caja 741). 
repobladora. Este final de la actividad foral estuvo marcado por un acontecimiento polftico: la invasión, conquista y parcial anexión del reino de Murcia por tropas aragonesas, a las ordenes de Jaime II. Este hecho, aparte de suponer una alteración de la realidad jurídica, fue más decisivo aún en el aspecto politico, pues buena parte del reino murciano, con algunas de las ciudades y villas más importantes, quedó ya detinitivamente anexionado a la Corona aragonesa. Aunque la conquista del reino de Murcia fue casi total, a excepción de las tierras manchegas y algunas encomiendas santiaguistas, la definitiva ocupación sólo se dio en el territorio hoy incluido en la provincia de Alicante, quedando el resto finalmente reintegrado a Castilla, según el acuerdo de Torrellas-Elche ${ }^{23}$.

En un primer momento, Jaime II confirmó todos sus fueros y privilegios a las ciudades y villas conquistadas, hasta que más adelante les otorgase ordenamientos forales propios, que resultaron de la refundición y adecuación de los anteriores ${ }^{89}$; se confirmaron también algunas mercedes y privilegios de carácter más puntual ${ }^{\text {on }}$.

\footnotetext{
"J. TORRES FONTES, La delimitación del sureste peninsular: Torrellas-Elche, 1304-1305, "Anales de la Universidad de Murcia", 1951, $3^{\circ}$ trimestre.

"J.M. del ESTAL, Confirmación de fueros a la ciudad y reino de Murcia por Jaime Il de Aragón (1296-1304), "MMM", IX (1982); Fueros y sociedad en el reino de Murcia bajo la hegemonía de Aragón (1296-1304), "AUAHM", 3 (1984). Sobre este aspecto y la actividad política y bélica vid. también: Fuero de adscripción por Jaime II de las villas de Orihuela y Alicante a la Corona de Aragón. "MMM", V (1980); y, Carla magna de Jaime Il de Aragón a las villas de Orihuela, Alicanie, Elche y Guardainar en su anexión al reino de Valencia (a. 1308). Arexo documental. "AUAHM", I (1982). De las confinnaciones de Jaime II estas son las que a nosotros interesan: confinnación de los fueros, franquicias, libertades, mercedes, honores y buenos usos, que recibiera la ciudad de Murcia de Alfonso X El Sabio, como hiciera el rey con otras ciudades del reino (J.M. del ESTAL, Confirmación, cit., pp. 248-249); confimación a la ciudad de Murcia de la partición y donaciones de carácter general y particular, así como demás bienes de los que se tomaron posesión, ésta la otorgó el rey dejando a salvo sus derechos reales (ibidem, p. 249); confirmación de la franquicia a los vecinos de Murcia para transitar con sus productos y mercancías por todo el reino de Murcia (ibidem, 250); así como seguridad a moros y judios (ibidem, 250-251), y vecinos de Murcia (ibidem, 251-252); exención de portazgo en todo el reino, salvo en las tierras del enemigo o en las cosas vedadas (ibidem 253-254). En el fuero del reino de Murcia, otorgado por Jaime II y compilado a partir de los primitivos fueros murcianos y del derecho valenciano, hoy perdido; se incorporaron algunos aspectos jurídicos relativos a la actividad económica y artesanal; caso de la concesión de amplias franquicias y libertades, como la exención de porthzgo, y de otras disposiciones de las que hemos hecho referencia mas amiba y que fueron incorporadas a este mareo general (J.M. del ESTAL, Fueros y sociedad, cil., p. 114 y s8.).

${ }^{\infty}$ De las que destacamos: Carta de Jaime II a lodos los mudéjares del reino de Murcia, con promesa de respetar sus bienes y posesiones si lo reconocian como soberano, confirmando sus derechos y costumbres (ibidem, 264-265); provisión real a favor del arraez de la Arrixaca, confirmándole el dominio de un homo y ciertas casas, en la ciudad (ibidem, 265-266); franquicia y libertad de movimiento para personas y mercancías, por tierras y aguas del reino de Murcia,
} 
Es de suponer que, tras la reintegración a la Corona castellana de las tierras murcianas, las disposiciones jurídicas y legales expedidas por Jaime II quedarían sin efecto, volviéndose por tanto al anterior derecho local, que en algún caso fue expresamente confirmado por Fernando IV ${ }^{91}$. En este sentido, dicho rey en 1304 otorgó un perdón general a los vecinos de Murcia, Lorca, Alhama y Molina2.

Por lo que respecta al trazado fronterizo, tras el pacto de Torrellas quedaron de forma diferente a los actuales los límites de las provincias de Alicante y Murcia. Villena y Elche pasaron a jurisdicción aragonesa, pero su propiedad pertenecía al noble castellano D. Juan Manuel. Cartagena permaneció también bajo soberanfa aragonesa, recuperada tras la sentencia de Elche; pero Jumilla se incorporo a Aragón y no fue finalmente recuperada

a los vecinos de Cartagena (ibidem, 269-270); carta de Jaime II al Justicia de Murcia, para ordenarle que se sirva de los fueros otorgados a la ciudad por Alfonso $X$, mientras se lleva a cato la compilación del fuero de Murcia, y que donde no basten, se atengan a los de Valencia (ibidem, 280); onden de Jaime II para la compilación de los fueros de la ciudad de Murcia (ibidem, 280-281); confirmación de casas, heredades y bienes a la ciudad de Cartagena, concedidos por Alfonso $X$ y sus sucesores (ibidem, 281); confirmación a los vecinos de Cartagena de sus fueros y franquicias, otorgados desde Femando III (ibidem, 282-283); exención a los vecinos de Mula de lezda y peaje, en el reino de Murcia; y confirmación de sus fueros y franquicias ( $i$ bídem, 284-285); confímación a los vecinos de Mula de sus privilegios, donaciones, buenos usos y costumbres, otorgados hasta la fecha por los reyes castellanos (ibidem, 285-286); carta de Jaime II al alcaide de Cartagena o a su lugarteniente, para prohibirles que graven en modo alguno fiscalmente a los vecinos de la ciudad contra sus fueros y costumbres, confirmados con anterioridad (ibidem, 288-289); sanción del Fuero del reino de Murcia, con original en la capital y copias en los restantes lugares (ibidem, 289-290). Confirmación por Jaime II al caballero Alfonso Pérez, por juro de heredad, de las posesiones que el infante D. Manuel tuvo en Murcia: casas, tierras, homos y molinos; confiscadas a D. Juan Manuel por su resistencia antiaragonesa (J.M. del EsTAL, Corpus documental del Reino de Murcia bajo la soberania de Aragón $1296-$ 1304), Alicante, 1985, pp. 247-249); carta de Jaime II al Bayle General del Reino de Murcia, notificándole la donación efectuada en una acequia de la Arrixaca para la construcción de unos molinos, al clérigo Bemardo Agustí (ibidèn, 283-289); concesión de lo anterior, fijándose el censo anual en un maravedi anual de oro (ibídem, 284-285) provisión real de Jaime II a favor de los monederos de Murcia, para que se les respeten los fueros por él otorgados y por sus antecesores (ibidem, 305-306); carta de Jaime II al Bayle de Murcia, facultándole para la acuñación de octavos de dobla, o 1/4 de dinar, áureos, tal y como se acostumbraba a hacer en la Arrixaca por los moros samacenos, al objeto de promover el comercio en la capital (ibidem, 306); carta de Femando IV de Castilla a Jaime II de Aragón, por la que dispensa del juramento de obediencia y fidelidad debidas a su Corona a las villas y lugares de Cartagena, Guardamar, Alicante, Elche, Orihuela, Elda y Villena, que pasaron a soberanía de Aragón; con excepción de la última, cuya propiedad se reserva D. Juan Manuel, en virtud del acuerdo de Torrellas ( $i$ bidem, 382-384); aunque más tarde Cartagena se reintegró al reino castellano.

${ }^{9} \mathrm{Tal}$ y como ocurrió con Lorca, a la que confirma sus fueros, privilegios y franquezas, "CODOM", V, p. 46 (Guadalajara, 14-III-1305). Caso también de la propia Murcia, a la que se dieron confirmaciones de varios privilegios concretos, ibídem, p. 53 (Medina del Campo, 18 V-1305), ibidem, p. 86 (Burgos, 4-VI-1308).

22J. TORRES FONTES, Repartimiento de Lorca, cit., pp. 100-101 (Agreda, 10-VIII-1304). 
hasta el reinado de Pedro I. Yecla, por el contrario se mantuvo bajo soberanfa castellana, siendo también propiedad de D. Juan Manuel. Cuando éste se casó con la hija de Jaime II cesaron las reivindicaciones aragonesas sobre Villena, aunque Elche sf acabo por ser cedida. Aunque la jurisdiccion teorica sobre Villena quedo incluida en Aragon, nunca dejo de disputarse entre ambos reinos, a pesar de los tratados; mientras que Fernando IV le confirmaba sus privilegios a la villa, Jaime II le concedía otros nuevos, a la vez que otorgaba nuevos titulos a su señor D. Juan Manuel; hasta que finalmente Villena, a través de su señor Juan Sánchez Manuel, reconoció por rey a Enrique II de Castilla, por lo que obtuvo en recompensa nuevos privilegios?

\section{Villas de señorlo}

En ellas la concesión y reproducción del derecho local reviste un menor interés para nuestro estudio, debido a que, en su mayoría, se trata de villas y aldeas de ámbito rural, con escasa o nula actividad artesanal. Además, la actividad normativa de los señores castellanos, aunque en ocasiones imito a la desplegada por la realeza, no entraño las caracteristicas que ésta otra tuvo; aparte de por el predominio rural entre las villas de señorío, porque los fueros y privilegios concedidos son mucho menos ventajosos que los reales, debido al mayor interés señorial por asegurarse el máximo de control político y económico de sus posesiones. Precisamente la mayor liberalidad de los territorios de realengo, revestida con la filosoffa del poder estatal y del derecho romano, marcaban la diferencia entre los señorios públicos y los privados; significando la alianza entre el pueblo y la corona.

Aparte de ser más restrictivos, los fueros señoriales no se solfan aplicar en su integridad. El caso más extremo resultó ser el del fuero de Cuenca, trasvasado desde tierras manchegas a las encomiendas santiaguistas del reino de Murcia, por una pura tradición de reproducción juŕdica. Este fuero, concedido con fines repobladores, no fue obice para la profundización en la presencia y exacción señorial, aumentada con el paso del tiempos.

\footnotetext{
93J. TORRES FONTES y A.L. MOUNA MOUNA, El adelanfamiento murciano, marca medieval de Castilla, "Historia de la Región Murcians", IV (Murcia, 1980), p. 24. Ginés SÁnCHEZ DONCEL, Un sethor medieval: Don Jwan Manuel, "AUAHM", 1 (1982), p. 95.

M. PESET, Los fueros de la frontera, cit., p. 35.
} 
A la vez que la repoblación concejil, matizada por cierto título dominical de sometimiento aldeano a la ciudad o villa, la formula señorial fue un elemento importante en la repoblación del siglo XIII. Sin que la diferencia entre la repoblación señorial y la real estribe en el sistema concejil, y recordando que el propio realengo se puede considerar un señorío feudal más. Al frente de cada señorío podía encontrarse un representante del titular, fuese éste civil o eclesiástico, que actuaba como verdadera autoridad local, en el orden territorial y personal; pero también existran concejos dependientes del poder del señor. El régimen señorial tiene un origen altomedieval, a partir de los dominios de explotación agrícola y la inmunidad, que llevaba aparejada facultades de gobierno al titular del dominio. Del control de la tierra dimanan los derechos coactivos que el señor ejerce sobre los moradores, en orden a su explotacion. Las necesidades repobladoras llevaron a la monarquia a conceder amplias extensiones de tierra a la nobleza, la iglesia o a las Ordenes Militares; quiénes las convirtieron en señorfos. En ellos se unen los derechos coercitivos emanados de abajo arriba (de la tierra a las personas), con otros de sentido inverso, derivados de la capacidad jurisdiccional y de gobierno, cedida por la monarquia junto al solar territorial ${ }^{95}$. Sin que ello presuponga la total desaparición de la autoridad real dentro de los mismos.

A veces, la población fue atraf́a, a estos nuevos señorfos, a través de la concesion de fueros y de la creación de municipios; algunas de estas villas incluso habran pertenecido con anterioridad al realengo, o les habra sido concedido su derecho local a imitación de algunas de este tipo. En el reino de Murcia, esta situación no fue infrecuente, y para su estudio cabe distinguir entre los señorfos laicos, de más marcado carácter urbano y anterior existencia realenga; y los eclesiásticos, propiedad de Ordenes Militares, con un muy marcado cariz rural.

A partir de las tierras del reino de Murcia se formo el núcleo principal de lo que llego a constituirse como el señorío de mayor extensión e importancia en Castilla. Se trata del futuro Marquesado de Villena, cuya extensión territorial llegó más allá de la propia Murcia, y cuyos obstentadores poseyeron otros numerosos señorfos lejanos, incluso en Aragon, que los convirtieron en aspirantes a la propia corona castellana, en parientes de reyes $y$ en sus validos.

\footnotetext{
${ }^{95}$ S. de MoxO, cit., pp. 387, 390-391.
} 
En el origen de este señorío se halla la propia corona, gracias a las generosas concesiones territoriales efectuadas por Alfonso $\mathrm{X}$ a su hermano, el infante D. Manuel. A éstas siguieron otras concesiones reales que supusieron la entrega incluso de villas de realengo, a dicho infante o a su hijo D. Juan Manuel. Este, ya en el siglo XIV, continuó la actividad iniciada por su padre, en materia jurídica, repobladora y política ${ }^{\%}$.

D. Manuel, en 1262, recibio el adelantamiento del reino de Murcia, asi como las villas de Elche, Crevillente, Aspe y Valle de Elda. Por las mismas fechas debió recibir Villena y más tarde de 1266, Almansa. Donde mejor se aprecia el paralelismo con la acción repobladora de la corona es en Elche, a la que don Manuel otorgó los mismos privilegios que Alfonso $\mathrm{X}$ concediera a Murcia. Lo que indica que, o bien ambas villas contaban con similares posibilidades económicas, o que se quería dar a este señorí la categorfa de una ciudad de realengo con funciones capitalinas ${ }^{97}$.

En 1267 don Manuel concedía a la villa de Elche el fuero de Sevi$11 a^{98}$. Concretamente se especifica que se trataba del mismo fuero "que el rey don Alfonso mio hermano dio al conceio de la noble cibdad de Seuilla". No sólo se trasvasó el derecho sevillano, sino que poco después además el murciano. En 1270 era el propio alfonso $X$ quien otorgaba al concejo de Elche los fueros y franqueas que tenía Murcia; esta concesión preciso además de la consiguiente confirmación del señor de la villa ${ }^{99}$. Otra confirmación dos años posterior tendría por finalidad recoger un nuevo privile-

\footnotetext{
Trabel GARClA DIAZ, Los señonios murcianos del infante don Manuel, "MMM", XIII (1986); M. PESET, La dualidad, cit.; A. PRETEl MARIN, Don Juan Manuel, señor de la llanura. Repoblación y gobiemo de la Mancha albacelense en la primera mitad del siglo XVV), Albacete, 1983; Andrés GIMÉNEZ SOLER, Don Juan Manuel. Biografía y estudio críico, Zaragoza, 1932. El origen real de este señorio no dejó de ser utilizado para los fines políticos de D. Juan Manuel, quien incluso jugó a la fantasía de imaginar a su padre convertido en rey de sus territorios murcianos; impresión esta que parece desprenderse de sus reflexiones sobre su familia y su linaje, contenidas en sus obras: "El libro de las armas" y "El libro Enfenido" [Don Juan Manuel. Obras completas, Jose Manuel BLECUA [ed.], I, Madrid, 1981; y A. PRETEl MARIN, Las armas de los Manuel en la heráldica municipal de la provincia de Albacete, "Al-Basit", 11, (1982)]. Lo cierto es que la concesión de fueros a sus villas por parte de don Manuel fue paralela a la del propio Alfonso X.

"II. GARCIA DIAZ, cit., pp. 190-193.

"CODOM", II, pp. 31-32 (Villena, 7-XII-1267).

99 "CODOM", III, p. 104 (Logroño, 27-I-1270). "CODOM", II, p. 38 (Villena, 5-VII-1270).
} 
gio entregado por el rey a los mercaderes murcianos ${ }^{100}$. Este extremo podría sugerir que todos los privilegios contenidos en el derecho local de Murcia y Sevilla fueron trasvasados a Elche, pues se dio esta nueva confirmación para recoger uno de nueva promulgación. La realidad no tuvo por qué ser ésta, pues hay que diferenciar entre los derechos y rentas reales, cuya exención corre a cargo de la corona, la cual no dejó de estar alentada por el poder señorial para beneficiar a sus señorfos; y los derechos cedidos por ésta a los señores, quienes, a pesar de los fueros y privilegios del derecho matriz, velaron por mantener inalterada su vigencia.

En el caso de Villena, la ficción igualitaria del fuero de Cuenca quedaba ya muy lejos. A pesar de ser una villa de frontera, a ésta se le concedió como a Elche un fuero de la familia toledana, pero en su rama más ventajosa, la cordobesa, y a través de Lorca, villa también excepcionalmente privilegiada por su condicion fronteriza; previamente en Villena se habia recibido, sin embargo, la rama sevillana más restrictiva. Fue en 1267 cuando don Manuel le concediera los privilegios de Elche y Murcia ${ }^{101}$, que no debieron bastar para sus objetivos, recurriéndose al derecho lorquino seis años más tarde ${ }^{102}$. Mientras que nuevamente en 1283 era en esta ocasión el infante don Sancho (futuro Sancho IV) quién, a petición de don Manuel, concedía otra vez a la villa todos los fueros, franquezas y libertades de Lorca; este hecho se explica en el enfrentamiento dinástico entre Alfonso $\mathrm{X}$ y su hijo, en el cual el hermano de aquél tomó partido por su sobrino. De nuevo, Sancho IV, ya rey, confirmaba lo anterior, en $1293^{103}$.

Las restantes villas del señorío apenas si presentan alguna población cristiana, siendo muy escasas las referencias documentales sobre sus usos forales ${ }^{104}$. Tampoco sabemos nada de la repercusión a nivel foral derivada del paso del realengo al señorío, sobre todo para villas como Almansa o

${ }^{100}$ Ibidein, p. 44 (ELche, 8-II-1272); I. GARClA DIAZ, cit., p. 193. Se trataba de una reducción del pago del diezmo ("CODOM", III, p. 58), que como renta real beneficiaba a los vecinos sin perjudicar los intereses del señor.

${ }^{101}$ A. Pretel, Conquista, cit., p. 199; y José María SOlER GARC1A, La relación de Villena de 1575, Alicante, 1974, p. 176 (Villena, 6-VII-1270).

${ }^{102}$ Ibidem, p. 207 (13-XI-1276); y en confirmación de D. Juan Manuel, "CODOM", II, pp. 63-64 (26-II-1307).

103"CODOM", IV, p. 6 (Palencia, 28-II-1283); J.M. SOLER, cit., pp. 209-210 (Valladolid, 22-V-1293).

${ }^{104} \mathrm{~A}$ no ser un nota sobre que los pobladores de Elda debían atenerse al fuero y alcaldes de Elche ("CODOM", II, p. 33). 
Chinchilla, que se integraron entre las propiedades de don Manuel, para las que se habla dado una mayor permanencia bajo la soberanfa real ${ }^{105}$.

Pasemos ahora a ocuparnos de los señoríos eclesiásticos, en Murcia mayoritariamente bajo el dominio de las Ordenes Militares.

En el reino de Murcia, por las propias características de su repoblación, la iglesia y las Ordenes Militares alcanzaron una gran importancia territorial, obteniendo de la realeza no solamente extensos dominios que convertir en señoríos, sino también abundantes bienes inmuebles en concejos de realengo, asi como rentas reales. A este respecto, el cabildo catedralicio de la iglesia de Cartagena se convirtió en gran propietario de inmuebles urbanos en la capital, mientras que la Orden de Santiago obtuvo propiedades en la huerta y campo de Murcia.

Como henos indicado, se trata de señorfos eminentemente rurales, con poca trascendencia artesanal, por lo que no dedicaremos a su estudio un amplio espacio. Se extendieron por amplias zonas del reino de Murcia y cambiaron frecuentemente de propietario, siendo varias las Ordenes presentes en el mismo y variables las encomiendas y concejos que les fueron cedidos, incluso algunos de anterior pasado realengo ${ }^{106}$.

En 1246 el maestre de Santiago concedía a la villa de Segura de la Sierra el fuero de Cuenca ${ }^{107}$, el cual se presenta claramente devaluado y

\footnotetext{
${ }^{105}$ Conocemos, sin embargo, las caracteristicas de la repoblación de Caudete, próxima a Villena pero bajo soberania aragonesa, gracias a la carta-puebla de su señor Juan García de Lián, de 1305 (J.M. SOLER, cil., p. 211); o la posterior actividad repobladora emprendida por don Juan Manuel, en la que por lo que respecta a la actividad foral destaca la concesión a Jorquera de las franquezas de las que gozara Chinchilla (A. PreTEL, Don Juan Manuel, cit., doc. 14).

${ }^{106}$ En 1243 la Orden de Santiago recibió la confimación de la ocupación de Segura de la Sierra, a la vez con los castillos de Moratalla, Socovos, Letur, Liétor, Nerpio, Taibilla, Yeste, y Huéscar, entre una larga lista de otras aldeas y localidades también incorporadas al concejo de Segura. Dos años más tarde, la misma Orden incorporaba a su propiedad Elda; y en 1255, por permuta, Callosa y Catral, que fueron entregadas a la corona en 1257 a cambio de Aledo. El Temple recibió en fecha indeterminada Caravaca, Cehegín y Bullas. Al igual que la Orden de Santiago Abanilla, que en 1281 permutó por Cieza; los prometidos territorios del Valle de Ricote fueron entregados en 1285, el mismo año que se anexionaba Orcera por permuta. Ceutí lo recibió en 1295. De este modo todo el Valle del Segura se convirtió en santiaguista, a excepción de Calasparra y Archena, que pertenecian a la Orden de San Juan, desde 1289 y a partir de 1295 la segunda. Durante lo siglos siguientes continuaron los esfuerzos repobladores y los cambios de propiedad [Maria del Pilar GIL GARClA, Las órdenes militares en el reino de Murcia (siglo XIII), "MMM", XIII (1986), p. 209 y ss.].

${ }^{107}$ Miguel RODRIGUEZ LLOPIS, La evolución del poblamiento de las sierras de Segura (provincias de Albacete y Jaén) duranse la baja Edad Media, "Al-Basit", 19 (1986), p. 25 (Bastida de Jaen, 12-II-1246).
} 
su concesión atiende más que nada a una inercia de reproducción juŕ́dica, puesto que el mismo habra constituido una herramienta repobladora en los territorios de la Orden, mucho antes de su instalación en el reino de Murcia. Por lo que ya en el privilegio de concesión se especifica que no se cedran a la villa las iglesias, tiendas, hornos, baños, carnicerfas, mercado, portazgo y la ida del rey; que evidentemente retenfa la Orden como rentas propias. Moratalla, que en un principio perteneció a Segura, también contó con el fuero de Cuenca, tal y como consta en una confirmación del maestre de Santiago ${ }^{108}$.

En 1257 Alfonso X entregaba al maestre y Orden de Santiago las villas de Aledo y Totana, con sus aldeas y términos, a cambio de Elda, Callosa y Catral ${ }^{109}$; la concesión incluía las rentas de las villas, el cuarto del arraez de Lorca, montes, pastos..., a excepción de moneda y justicia, que retenfa el rey como en otros lugares de la Orden. En 1243 el maestre de Santiago concedía a Aledo el fuero de Lorca ${ }^{110}$, junto al que se incluian sus franquezas, libertades, usos y costumbres; pero dudamos que se trasvasasen integras las amplias ventajas lorquinas, porque por ejemplo en lugar de exención general de portazgo o diezmo sólo se concedió, como en Córdoba, la exención de los mismos en la permuta de cautivos; a la vez que la Orden retenia los molinos, almazaras, hornos, montazgos, portazgos y dehesas del concejo. Según el derecho cordobés, ningún moro, judfo o cristiano nuevo podía tener mandato alguno sobre cristiano, a excepción de si era almojarife de la Orden: "por razón de nuestros derechos". Como en Lorca, las obras de los muros de la villa debran pagarse de las rentas reales, ahora señoriales, aunque a diferencia de ésta, la Orden sí retuvo el diezmo de las heredades de los vecinos.

Ya dijimos en el apartado anterior como fue Sancho IV quién otorgo el título de villa a Caravaca, a la vez que le concedía el fuero de Alcaraz y como aldeas a Cehegín y Bullas. En fecha indeterminada, la Orden del Temple habra recibido Caravaca, con Cehegín y Bullas, con las que formo

\footnotetext{
${ }^{108}$ M. RODRIGUEZ LLOPIS, Documentos para la historia medieval de Moratalla, Murcia, 1988, pp. 70-71 (Mérida, 13-III-1331).

109 Juan BAGUENA, Aledo. Su descripción e historia, Murcia, 1980, pp. 261-263 (Cartagena, 14-IV-1257).

${ }^{110}$ Ibidem, pp. 266-267; y "CODOM", II, pp. 100-102 (Almendros, 18-VIII-1293).
} 
una bailía ${ }^{111}$; se apunta la fecha de 1244 como en la que probablemente esta Orden obtuviera estos territorios, en la persona de su maestre don Martín Martínez. Más adelante, fue en 1286 cuando Sancho IV quitó esta bailia al Temple, haciéndola realenga, por haber entregado el castillo de Bullas a los moros ${ }^{112}$. Si Caravaca perteneció en depósito a la Orden de Santiago antes de 1344 es un extremo no aclarado, lo cierto es que Cehegín parece que se independizó de la misma en 1307, cuando otra vez intervino el Temple, cuyo maestre concedió a la villa el fuero de Alcaraz ${ }^{113}$; pero según se indica, este fuero ya le habra sido otorgado por maestres anteriores, seguramente porque lo recibiera de Caravaca de la que fue aldea. Los vecinos de Cehegín debran entregar sus derechos a la Orden, de la que eran vasallos $^{114}$. En 1317 el maestre, en esta ocasión de Santiago por haber pasado a esta última la villa, confirmaba algunos preceptos contenidos en el fuero de Alcaraz, existiendo otras confirmaciones posteriores; hasta que en 1344 alfonso XI concedia de forma definitiva las tres encomiendas juntas, Caravaca, Cehegín y Bullas a la Orden de Santiago ${ }^{115}$.

En 1281, Abanilla que también pertenecía a la Orden de Santiago, era permutada por Cieza ${ }^{116}$. Año este en el que se le prometra a dicha Orden, por parte del todavia infante don Sancho, la entrega del Valle de Ricote, Calasparra, Librilla y Alhama ${ }^{117}$; con sus términos, hornos, molinos, tiendas, tahonas, montazgos, portazgos y derechos. De esta promesa efectuada en pleno enfrentamiento sucesorio contra su padre, finalmente sólo se entrego Ricote, con los susodichos hornos, molinos, tiendas, etc.; a

\footnotetext{
"'Lope Pascual Martinez, Los templarios en el reino de Murcia, "Las Ordenes Militares en la Península durante la Edad Media", Actas del Congreso Intemacional Hispano-Portugués, Barcelona, 1981, pp. 689-690.

${ }^{112}$ Emilio SÁzZ SÁNCHEZ, Privilegios de la Orden de Santiago a Caravaca, "Hispania", 6 (1942), p. 126.

${ }^{113}$ bidem (Zamora, 15-V-1307); J. TORRES FONTES, Documentos, cil., pp. 97-99.

${ }^{114}$ Ibidem, pp. 101-102 (Montiel, 2-IV-1315).

115 Bbidem, pp. 103-104 y 117-121. En el privilegio de concesión, sin embargo, se indica que estas villas pertenecian a la comna, lo que avalaria la tesis de que se cedieron a Santiago en depósito. La concesión de Alfonso XI incluía hornos, aceñas, molinos, pechos, derechos, rentas, diezmos, etc., tal y como los tuviera el Temple, a excepción de moneda, aposentamiento, alzadas, minas...

116" CODOM", III, pp. 158-160 (Toledo, 24-IV-1281).

117"CODOM", IV, pp. $1-2$ (Agreda, 25-III-1281)
} 
cambio de la prometida Librilla se concedio Castel ${ }^{118}$; mientras que Calasparra fue finalmente entregada por Sancho IV a la Orden de San Juan ${ }^{119}$, también con sus derechos; por último, Alhama fue otorgada por Fernando IV a Lorca' ${ }^{120}$.

Otras concesiones fueron: Ceutr a la Orden de Santiago y Archena a la de San Juan ${ }^{121}$; Alguazas a la Iglesia de Cartagena ${ }^{122}$; Fortuna fue vendida por el rey moro a don Patricio de Momport ${ }^{12}$, luego concedida a la Orden de Santiago en $1307^{124}$, dejada sin efecto esta concesión en $1308^{125}$ y revocada en $1311^{120}$.

\section{CONCLUSIÓN}

Para concluir podríamos trazar un mapa en el que se reflejase la acción repobladora a partir de los ordenamientos forales:

El fuero de Cuenca y sus derivados predominan en el norte del reino (actual provincia de Albacete), as En la primera zona su concesión se corresponde con los primeros esfuerzos repobladores y la fijación de un marco ventajoso a zonas peligrosas de frontera; el cual luego fue rebajado conforme retrocedía ésta. En la segunda zona, el fuero ya devaluado se otorga mecánicamente por las Ordenes Militares, como mera reproducción jurídica.

Las otras regiones fronterizas del reino: Lorca, Villena, Yecla, Almansa, Alicante y Cartagena (estas últimas también con frontera marítima) recibieron el fuero de Córdoba. Se trata del más ventajoso derecho toledano, el más apropiado de esta familia para atraer población a inseguras zonas de

\footnotetext{
${ }^{118}$ Ibidem, pp. $44-47$ (Sevilla, 19-XI-1285). Ibidem, p. 2.

"19idem, pp. 73-76 (San Sebastián, 9-VI-1289).

120"CODOM", V, pp. 30-31 (Palencia, 23-X-1299).

${ }^{121}$ M.P. GIL Garcia, cit., p. 211.

122"CODOM", III, pp. $94-96$ (Jaen, 19-V-1267).

${ }^{123} \mathrm{~J}$. TORRES FONTES, Fortuna en los siglos XIII y XIV, "Murgetana", 28 (1968), pp. 68-69 (Murcia, 3-VI-1295).

${ }^{124}$ Jbidem, pp. 74-78 (Tordehumos, 14-XII-1307).

125"CODOM", V, p. 85 (Burgos, 4-VI-1308).

${ }^{126} \mathrm{~J}$. TORRES FONTES, cil., pp. 78-79 (Burgos, 19-XI-1311).
} 
frontera; como se deduce de su concesión a Lorca, que fue además ampliamente privilegiada, la más peligrosa frontera limitrofe con Granada junto con las encomiendas santiaguistas aforadas a Cuenca. Fue precisamente de Lorca de donde se trasvas 6 este fuero, junto con sus amplios privilegios, a las villas fronterizas con el reino de Valencia: Villena (a la que se amplió con ello el más restrictivo marco sevillano-murciano) y Yecla. En el caso de Almansa, al no resultar la frontera valenciana de excesivo peligro, no fue preciso mantener la vigencia de su fuero de Cuenca, entrando en la familia cordobesa a través del fuero de Alicante, fronteriza asimismo esta última con Valencia. La cual, junto con Cartagena, constituyeron la frontera marftima, a la que unieron sus necesidades portuarias; por lo que a ellas se adaptó también convenientemente el fuero de Córdoba.

Las restantes zonas del interior del reino, menos inseguras y más atractivas economicamente para los repobladores, obtuvieron el menos ventajoso de los derechos toledanos, el fuero de Sevilla. Lo que ocurrio con Murcia, de donde se extendio a su término (Ricote y Molina) y Mula (antes aforada innecesariamente ya a Cordoba); y más tarde a Orihuela (que lo compagino con el derecho alicantino), Elche y finalmente a Jumilla.

Se puede afirmar pues, que la ocupación, repoblación y organización económica de los núcleos de población del reino de Murcia, durante el siglo XIII, se hizo de manera uniforme y planificada, intercambiándose experiencias en lugares con caracteristicas similares, a los que se dotó del mismo reglamento juridico, parecido derecho local o similares privilegios. Ello debio atender a un plan preconcebido, sobre todo en la persona de Alfonso $\mathbf{X}$, que ante los mismos fallos o desviaciones era corregido con idénticas soluciones. Esta estructuración foral estuvo además relacionada con otros varios aspectos, sobre todo el defensivo-militar, que implicaba relaciones sociales derivadas del papel de la caballerfa villana.

De forma que nos hallamos ante una primera integración y configuración regional, condicionada por las circunstancias geoestratégicas, bélicas, politicas y económicas: y remarcada por un común ordenamiento foral. El artifice de esta integración y de dicha planificación fue el rey Alfonso X El Sabio, continuador de su padre, Fernando III, y ayudado por su hermano, el infante don Manuel. 


\section{RESUMÉ}

Dans ce travail on analyse l'organisation juridique du royaume de Murcia pendant sa conquête, les lois spéciales accordées et les activités commerciales et artisanales contenues dans cette organization.

D'autres aspects étudiés sur les ordonances de ces lois sont: leur origine, les familles légales dont elles provenaient et les causes de leur concession en fonction des besoins de repeuplement, du péril du territoire, du developpement economique ou d'objectifs politiques.

Ainsi, la famille de Cuenca, qui favorisait l'activité lainière, avec ses trois juridictions de Cuenca, Alcaraz et Alarcón, s'adapta mieux aux territoires dangereux du nord a a ceux de l'Ordre de Saint Jacques. La famille de Toledo, la plus restrictive dans ses droits, avec ses juridictions de Toledo, Seville et Córdoba, s'applica pour obtenir des rentrées fiscales plus importantes en imposant leurs activités commerciales a artisanales.

Cependant, quelques villes reçurent jusqu'à trois ordonnances différentes, dérivées des familles differentes avec un traitement inégal de leurs activités économiques.

\section{SUMMARY}

The essay analyses the legal framework of the kingdom of Murcia while it was under occupation and looks at the laws and decrees drawn up and the commercial and artisanal activities they covered.

Among other aspects of this legal codes covered here are their origin, the legal families they came from and the reasons for them being conceded in accordance with the need for repopulation, the level of danger to which the area was exposed, the economic developed envisaged and political aims.

As such, the Cuenca legal family with jurisdiction over Cuenca, Alcaraz and Alarcón, which favoured wool-based activities, adapled more easily to the unsafe frontier areas to the North and those of the Order of Santiago. The Toledo family with jurisdiction over Toledo, Sevilla and Córdoba was more restrictive in its laws which were aplied in the more affluent and heavily populated southern cities. By taxing commercial and artisanal activities, it obtained higher levels of tax-derived income.

However, some communities received up to three different families and jurisdictions meaning that their economic activities were given unequal treatment. 